\title{
Addressing a Humanitarian Relief Chain Considering Uncertain Demand and Deprivation Costs by a Hybrid LP-GA Method: An Earthquake in Kermanshah
}

Amin Forughi ( $\nabla$ aminforughiii@yahoo.com )

Islamic Azad University https://orcid.org/0000-0002-3453-9931

Babak Farhang Moghaddam

Institute for Management and Planning Studies

Mohammad Hassan behzadi

Islamic Azad University

Farzad movahedi sobhani

Islamic Azad University

\section{Research Article}

Keywords: Robust Optimization, Relief logistic, Humanitarian Relief Chain (HRC), Operational and Disruptive risk, Hybrid LP-GA approach, Best worst method (BWM).

Posted Date: September 8th, 2021

DOI: https://doi.org/10.21203/rs.3.rs-656906/v1

License: (c) (1) This work is licensed under a Creative Commons Attribution 4.0 International License.

Read Full License 
Addressing a humanitarian relief chain considering uncertain demand and deprivation costs by a hybrid LP-GA method: An earthquake in Kermanshah

3

\author{
Amin Foroughi ${ }^{1 *}$, Babak Farhang Moghaddam ${ }^{2}$, Mohammad Hassan Behzadi ${ }^{3}$, Farzad Movahedi \\ Sobhani $^{4}$ \\ ${ }^{1 *}$ Department of Industrial Engineering, Science and Research Branch, Islamic Azad University, Tehran, \\ Iran, Email: aminforughiii@yahoo.com \\ ${ }^{2}$ Institute for Management and Planning Studies (IMPS), Tehran, Iran. \\ Email: farhang@imps.ac.ir \\ ${ }^{3}$ Department of Statistics, Science and Research Branch, Islamic Azad University, Tehran, Iran. \\ Email: behzadi.stat@gmail.com \\ ${ }^{4}$ Department of Industrial Engineering, Science and Research Branch, Islamic Azad University, Tehran, \\ Iran, Email: Fmovahedi@iau.ac.ir \\ *Corresponding author: Amin Foroughi, Email: aminforughiii@yahoo.com, https://orcid.org/0000-
} 0002-3453-9931.

\title{
Abstract
}

Today, a great deal of attention to numerous disasters such as earthquakes, floods and terrorist attacks is motivated by humanitarian logistics. A comprehensive plan for relief logistic items under uncertainty is a challengeable concern for both academic and logistics practitioners. This study contributes another robust plan for the humanitarian logistics for the earthquake disaster in Kermanshah, Iran. The proposed framework evaluates both operational and disruption risks simultaneously to study the Humanitarian Relief Chain (HRC) network after an earthquake. The main novelty is the simultaneous consideration of the deprivation costs and demand under uncertainty. The deprivation cost leads to a reduction in high social costs for the decision-makers of the HRC. The proposed HRC also guarantees the delivery of the essential supplies to beneficiaries under both operational and disruption risks. As an optimization model, it seeks to minimize total costs consisting of inventory holding cost, shortage cost, deprivation costs and transportation cost and maximizes each facility's weighted resilience level as the second objective. A robust optimization model is established to deal with uncertain levels of the transport network paths, supply condition, amount of demand and deprivation costs which are assumed uncertain. The resilience parameters used for the second objective are obtained by a Best Worst Method (BWM). Another significant contribution was a hybrid approach combining the LP-metric method and Genetic Algorithm (GA) as the LP-GA approach for optimizing large-scale instances. Regarding the analyses, including tuning, validation and comparison of the proposed approach, its performance is showed by several standard multi-objective assessment metrics. As a final point, the achieved outcomes demonstrate that the suggested model is highly sensitive to uncertain parameters. This encourages further development and application of the proposed HRC with the use of a hybrid LP-GA approach as a strong technique for solving optimization problems.

Keywords: Robust Optimization; Relief logistic; Humanitarian Relief Chain (HRC); Operational and Disruptive risk; Hybrid LP-GA approach; Best worst method (BWM). 
Humanitarian logistics is an important aspect of relief operations when natural and/or manmade disasters occur. In general, and in common terms, humanitarian logistics deals with providing and transferring the required resources and goods to the injured individuals. However, this is only one aspect of humanitarian logistic and there is in fact more aspects to be considered, such as resource dope, optimization, inventory management and information exchange. Thus, a broader definition of humanitarian logistics which includes planning process, execution and control the resource flow, and accessibility to the relevant information at different stages of operation, is required to provide a successful performance for the injured individual (Behl and Dutta 2018). So most of the keywords used in the humanitarian supply chain are shown below (see Fig. 1).

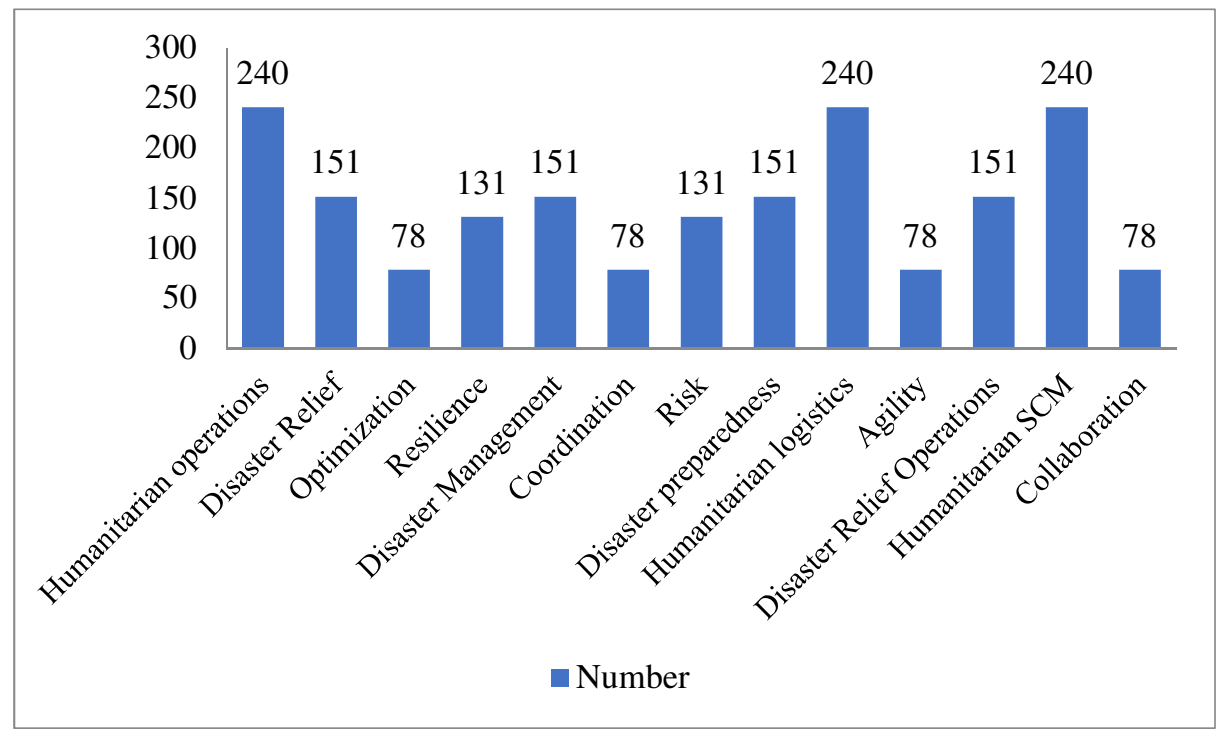

Fig. 1. Distribution of clustered keywords used in the humanitarian supply chain

Since one of the effective measures to reduce the effects of disaster has been the humanitarian supply chain, it has interested the researchers. It has also made it extremely difficult to determine effective measures for logistics operations due to the risks and uncertainties of complex events and operations in the humanitarian supply chain. Plus, due to the short duration and the unpredictable changes in supply and demand (Elluru et al., 2017), humanitarian aid chains are much more efficient than the commercial supply chain. Lack of resources in a disaster situation can have direct consequences, so focusing on HRC is more efficient in the supply chain, which plays an important role in countering uncertain demand (Kaur and Singh 2016). To respond to emergency needs, distribution, etc. at specific times and conditions that have been defined as a flexible response when an unexpected event occurs as a humanitarian supply chain capability (Kunz and Gold (2017). Supply disturbances occur during or after a disaster when the HRC is not very reliable. Also, supply disruptions lead to high increase social costs, which also worsening supply delays. Since the collection and production of adequate relief resources in the short term are cases where humanitarian assistance to it is needed, thus increasing the demand for emergency production. As a result, humanitarian supply chain capacity will be close to its peak (Galindo and Batta 2013). Therefore, this research designs a humanitarian logistics network consisting of central warehouses (CWs) and local distribution centers (LDCs) and some parameters such as availability level of the transport network paths, supply condition, amount of demand, and deprivation costs are assumed under uncertainty. 
Therefore, the problem uses a novel robust optimization approach to manage the recommended model under uncertain conditions. The main aims of this research's model are optimizing the total costs of the relief chain and the weighted resilience level of each facility (CW/LDC). The resilience parameters are studied by the Best Worst Method (BWM) in the second objective for weighting parameters and making decisions. Moreover, another main novelty of this paper is a hybrid approach combining the LP-metric method and the Genetic Algorithm (GA) as one of the well-known evolutionary algorithms. The proposed hybrid LP-GA is used to verify the model for solving a case study in an earthquake of Iran. Generally, the main highlights are:

$\checkmark$ A bi-objective robust optimization model for the humanitarian relief logistics considering uncertain deprivation costs and demand is developed.

$\checkmark$ The BWM studies the resilience parameters and a hybrid LP-GA measure is created to manage the recommended model.

$\checkmark$ A real-life case study of an earthquake in Kermanshah, Iran, is proposed to validate our methods.

\section{Literature review}

Every year, natural disasters affected many areas, including the world and injury, death, property destruction, and disruption of daily activities caused by these events. Generally, the disasters are divided into two key groups consist of natural (for example, earthquake, famine, tsunami, cyclone, hurricane, flood, etc.), disease (like plague or malaria), manmade disasters and extreme poverty situations (Galindo and Batta 2013). By way of example, Mohasel afshar (2011) reports that in 2005 near 489 disasters in 127 countries all-over the world occurred, leading to 160 million injuries and the death of 104,698 people. Following the reports of the Natural Disaster Database, only earthquakes have killed over seventy thousand people in the last two decades. Due to the inevitability of the devastating effects of the disaster, these effects can be alleviated by a preventive measure and the formulation of an appropriate preparation plan. Therefore, it is essential to take proper action for such disasters. Also, since Iran's geographical situation has made it a disaster-prone country in the world, each year causing devastating earthquakes and the resulting crisis, resulting in huge harm to the individuals and the country's economy, hence, the creation of an integrated humanitarian relief chain will strengthen the management of natural disasters, especially earthquakes (Zokaee et al. 2016).

102 Several key components in relief operations are that crisis managers should consider them and Humanitarian

103 Relief Logistics as the most important element. Logistics planning in disaster relief includes sending numerous 104 parts, including rescue equipment, medicine, food, and rescue teams, from several supply sources to many 105 distribution points in damaged fields by a chain structure (Caunhye et al., 2012).

106 Lately, a three-level model of relief chain that includes distribution centers, suppliers, and damaged regions is 107 recommended by Zokaee et al. (2016). They offered a MILP deterministic model applying strong optimization. 108 Their offered problem efforts to optimize the relief chain's costs and consider a penalty for shortages of 109 commodities to optimize the satisfactory level of people in the affected regions. Also, Sahebjamnia et al. (2016) 110 recommended a hybrid system based on decision support to design an HRC with three echelons. They made a 111 clear analysis to show the exchange between reactionary and performance of the planned HRC using several key 112 performance criteria consist of cost, coverage, and reaction time. Also, to verify the model, a case study is 113 demonstrated using stochastic data. Fahimnia et al. (2017), designed a stochastic bi-objective blood supply chain 114 (BSC) to lower the total cost and delivery time of BSC in catastrophes. They combined the Lagrangian 
115 relaxation and $\mathcal{E}$-constraint methods to address the suggested model. Maharjan and Hanaoka (2017), had the

116 intention to define the optimal location and warehouse number to be constructed for an HRC in different areas

117 of Nepal. Simplex algorithm with branch and bound is applied to solve their proposed model. Moreover,

118 developed two bi-level models in their two recent types of research; that the first model, Safaei et al. (2018),

119 seeks to minimize operational costs and to use the TOPSIS method choose the suppliers with lower risk and by

120 KKT method is solve; while the second research Safaei et al. (2018), attempt to minimize operational costs and

121 unsatisfied demand and to use goal programming approach and KKT method is solved. Cao et al. (2018)

122 presented a multi-objective mathematical model to raise the lowest victims' perceived moral and lower

123 respectively the largest deviation on victims' perceived satisfaction for all demand points and sub-phases. Their

124 model is solved using a genetic algorithm. A multi-echelon MILP is suggested by Tavana et al. (2018), to design

125 a humanitarian logistic network that considers pre-and post-disaster management. Their proposed model was

126 solved by using an $\varepsilon$ - constraint method, NSGA-II, and a modified NSGA-II. Nikkhoo et al. (2018), proposed a

127 multi-echelon supply chain by utilizing a quantity flexibility contract (QFC) consist of a relief organization, one

128 supplier, and affected areas to coordinate sequence activities. Ghatreh Samani et al. (2018), designed the blood

129 supply chain network by a multi-objective mixed-integer linear programming model in order to minimize total

130 cost, the maximum unsatisfied demand, and time span. They demonstrated the applicability of their model to a

131 real study in Mashhad, Iran. A bi-objective mixed-integer mathematical programming model under uncertainty

132 is proposed by Ghasemi et al. (2019), to minimize the location-allocation total cost of facilities and the amount

133 of relief supplies shortage. Sarma et al. (2019) preset two new mathematical models for humanitarian logistic

134 under uncertainty. In the first study, Sarma et al. (2019) aim to minimize the total cost and the redistribution

135 total time. Then, three different approaches are used to solve the model: Neutrosophic programming approach,

136 goal programming, and Pareto optimal solution approach; in the second study, Sarma et al. (2019), seeks to

137 minimize the total cost and total time of the operation of relief logistic in association with a non-governmental

138 organization (NGO), Then, the model solved using a different method. Shin et al. (2019) proposed a MILP

139 mathematical model to provide optimal scheduling considering reconstruction and delivery. An ant Colony

140 Optimization algorithm is utilized to resolve the model. Some studies proposed a humanitarian supply chain

141 network to minimize total costs and consider location-allocation costs of facilities, operating costs of active

142 facilities, Transportation costs, and shortage costs as a cost of the supply chain (e.g., Charles et al. (2016)). In

143 general, mentioned researches considered variables like location of facilities, inventory, demand shortage,

144 allocation and production line. Also, some studies aimed to maximize the covered demand and they considered

145 location-allocation, the flow of product or material, and demand shortage as variables (see Ransikarbum and

146 Mason (2016)). In this field, some researchers developed multi-objective mathematical models in order to

147 follow different goals simultaneously. For example, Tavana et al. (2018), put forward a multi-objective mixed-

148 integer programming model to lower total costs of relief logistics and minimize the operational relief time. They

149 considered location-allocation, demand shortage, unused material or product and amount of wasted material or

150 product as decision variables. Nezhadroshan et al. (2020) proposed an HRC with the use of a stochastic-

151 possibilistic programming approach. They used a hybrid of DEMATEL and ANP methods to solve the model

152 for a case study of the Mazandaran earthquake. A summary of several relevant papers in HRC is illustrated in 153 Table 1. 
Table 1. A concise review on related researches

\begin{tabular}{|c|c|c|c|c|}
\hline \multirow{2}{*}{$\begin{array}{l}\text { Authors/Year } \\
\text { Barzinpour and } \\
\text { Esmaeili (2014) }\end{array}$} & \multicolumn{2}{|c|}{ Disaster type } & Solution approach & \multirow[t]{2}{*}{ Case study } \\
\hline & Population, Costs & Earthquake & Goal programming & \\
\hline Hu et al. (2014) & $\begin{array}{l}\text { Opening cost, } \\
\text { travel evacuation } \\
\text { distance }\end{array}$ & Earthquake & Genetic algorithm & $\begin{array}{l}\text { Chaoyang } \\
\text { District of } \\
\text { Beijing }\end{array}$ \\
\hline $\begin{array}{l}\text { Jabbarzadeh et al. } \\
(2014)\end{array}$ & Costs & Earthquakes & Branch and bound & Iran (IBTO) \\
\hline $\begin{array}{l}\text { Akgün et al. } \\
(2015)\end{array}$ & Risk & Earthquakes & Exact algorithm & Turkey \\
\hline $\begin{array}{l}\text { Kedchaikulrat and } \\
\text { Lohatepanont } \\
(2015)\end{array}$ & $\begin{array}{l}\text { Structure cost and } \\
\text { AHP score }\end{array}$ & General & Pareto dominance & $\begin{array}{l}\text { Thai Red } \\
\text { Cross }\end{array}$ \\
\hline $\begin{array}{l}\text { Khayal et al. } \\
(2015)\end{array}$ & Costs & General & Exact algorithm & $\begin{array}{l}\text { South } \\
\text { Carolina, USA }\end{array}$ \\
\hline Kilci et al. (2015) & $\begin{array}{l}\text { Weight of } \\
\text { operating candidate } \\
\text { shelter }\end{array}$ & Earthquakes & Exact algorithm & $\begin{array}{l}\text { Kartal, } \\
\text { Istanbul, } \\
\text { Turkey }\end{array}$ \\
\hline $\begin{array}{l}\text { Moeini et al. } \\
(2015)\end{array}$ & $\begin{array}{l}\text { Warehouse } \\
\text { operation, } \\
\text { transportation time }\end{array}$ & General & Exact algorithm & $\begin{array}{l}\text { Val-de- } \\
\text { Marene, } \\
\text { France }\end{array}$ \\
\hline $\begin{array}{l}\text { Verma and } \\
\text { Gaukler (2015) }\end{array}$ & $\begin{array}{l}\text { Weight distance, } \\
\text { Un-weight distance }\end{array}$ & Earthquakes & $\begin{array}{l}\text { Weiszfeld } \\
\text { algorithm, } \\
\text { heuristics }\end{array}$ & California \\
\hline $\begin{array}{l}\text { Salman and Yücel } \\
\text { (2015) }\end{array}$ & $\begin{array}{l}\text { Transportation, } \\
\text { Unmet demand, } \\
\text { Holding }\end{array}$ & Earthquakes & $\begin{array}{l}\text { Lagrangian, } \\
\text { L-shaped method }\end{array}$ & Istanbul \\
\hline $\begin{array}{l}\text { Manopiniwes and } \\
\text { Irohara (2016) }\end{array}$ & $\begin{array}{l}\text { Opening cost, } \\
\text { shipping cost, } \\
\text { response time }\end{array}$ & Flood & Goal Programming & $\begin{array}{l}\text { Chiang Mai, } \\
\text { Thailand }\end{array}$ \\
\hline $\begin{array}{l}\text { Marcelin et al. } \\
(2016)\end{array}$ & & Hurricane & & $\begin{array}{l}\text { Leon country, } \\
\text { Florida }\end{array}$ \\
\hline $\begin{array}{l}\text { Ransikarbum and } \\
\text { Mason (2016) }\end{array}$ & $\begin{array}{l}\text { Transportation, } \\
\text { Shortage, Delay }\end{array}$ & Hurricane & Exact algorithm & South Carolina \\
\hline $\begin{array}{l}\text { Fahimnia et al. } \\
(2017)\end{array}$ & Cost, delivery time & general & hybrid solution & $\begin{array}{l}\text { Numerical } \\
\text { experiments }\end{array}$ \\
\hline Cao et al. (2018) & victims' perceived & Earthquake & Genetic algorithm & Wenchuan \\
\hline
\end{tabular}




\begin{tabular}{|c|c|c|c|c|}
\hline & $\begin{array}{l}\text { satisfaction, } \\
\text { deviation on } \\
\text { perceived } \\
\text { satisfaction }\end{array}$ & & & $\begin{array}{l}\text { Earthquake, } \\
\text { China }\end{array}$ \\
\hline $\begin{array}{l}\text { Tavana et al. } \\
(2018)\end{array}$ & Costs, Time & General & $\begin{array}{l}\text { E-constraint, } \\
\text { NSGA-II, modified } \\
\text { NSGA-II }\end{array}$ & $\begin{array}{l}\text { Numerical } \\
\text { experiments }\end{array}$ \\
\hline $\begin{array}{l}\text { Ghatreh Samani et } \\
\text { al. (2018) }\end{array}$ & $\begin{array}{l}\text { Cost, Unsatisfied } \\
\text { demand, Time span }\end{array}$ & Earthquakes & $\begin{array}{l}\text { interactive fuzzy } \\
\text { solution approach }\end{array}$ & Mashhad, Iran \\
\hline $\begin{array}{l}\text { Ghasemi et al. } \\
(2019)\end{array}$ & Costs, Shortage & Earthquake & $\begin{array}{l}\text { MMOPSO, NSGA- } \\
\text { II, } \varepsilon \text {-constraint }\end{array}$ & Tehran- Iran \\
\hline $\begin{array}{l}\text { Deepshikha et al. } \\
\text { (2019) }\end{array}$ & Costs, Time & General & $\begin{array}{l}\text { Neutrosophic } \\
\text { programming, goal } \\
\text { programming, } \\
\text { Pareto optimal } \\
\text { solution }\end{array}$ & $\begin{array}{l}\text { Numerical } \\
\text { experiments }\end{array}$ \\
\hline $\begin{array}{l}\text { Nezhadroshan et } \\
\text { al. (2020) }\end{array}$ & Costs, Time & Earthquakes & $\begin{array}{l}\text { Hybrid } \\
\text { DEMATEL and } \\
\text { ANP }\end{array}$ & $\begin{array}{l}\text { Mazandaran- } \\
\text { Iran }\end{array}$ \\
\hline This study/2020 & $\begin{array}{l}\text { Cost, weighted } \\
\text { resilience level }\end{array}$ & Earthquakes & $\begin{array}{l}\text { LP-GA, } \\
\text { Heuristics , } \\
\text { metric }\end{array}$ & $\begin{array}{l}\text { Kermanshah - } \\
\text { Iran }\end{array}$ \\
\hline
\end{tabular}

To show the contributions of this research in comparison with the aforementioned works in the literature, some points can be highlighted. First, this paper considers a designation of humanitarian logistics network consisting of central warehouses (CWs) and local distribution centers (LDCs) and some parameters assumed under uncertainty. Second, the model is formulated by a novel robust optimization as a bi-objective model to minimize the total cost and maximize resiliency. Third, the BWM is used to assess the resilience parameters and then a hybrid LP-GA method is developed to obtain a flexible and more trustworthy output. Finally, a real-life case study of Kermanshah, Iran for an earthquake is employed to show the applicability of our framework.

Due to the nature of the problem and the proposed mathematical model, also the lack of response in large-size problems, the solution to this problem is to use a heuristic approach as a combination of LP-metric and GA. Moreover, according to the relevant literature explored in Table 1, the employment of a robust optimization approach would result in a resilience relief logistic. The objectives of the previous studies investigated in Table 1 mostly consider the minimization of the total cost. Also, the resilience parameters are used by the approach of Best Worst Method (BWM). In this regard, this goal is also presented in this paper as a special contribution. Regarding the nature of the problem expressed in this paper, the simultaneous consideration of deprivation costs and demand under uncertainty expresses the special contribution of this study. 
$\checkmark$ Because of the presence of nonlinear constraints, including uncertain parameters in the suggested model as a Mixed Integer Non-Linear Programming (MINLP), an innovative, robust optimization model is employed heuristically to reduce the computational time against uncertainty's different levels.

$\checkmark$ Besides, uncertainty in some parameters such as availability level of the transport network paths, supply condition, amount of demand, and deprivation costs.

$\checkmark$ This study, among the first papers, considers deprivation costs as the uncertain parameters in the literature.

\section{Problem description}

184 Here, as illustrated in Fig. 2, three stages for the proposed disaster relief logistics network are considered. These stages contain CWs and strategic stocks, the suppliers set, and the final stage includes local distribution centers (LDCs) in the areas damaged by a disaster. Therefore, suppliers (e.g., governments, aid organizations, etc.) may play a serious role in the network and ready the essential supplies of individuals in dilapidated regions; these individuals can consider as the main customers of a normal distribution. CWs include airports, warehouses, and train and bus stations. The application of LDCs is completely admissible because several inactive CWs in the absence of the crises are impossible. Indeed, the use of available public places could be a proper choice to deal with a crisis situation (Görmez et al., 2011).

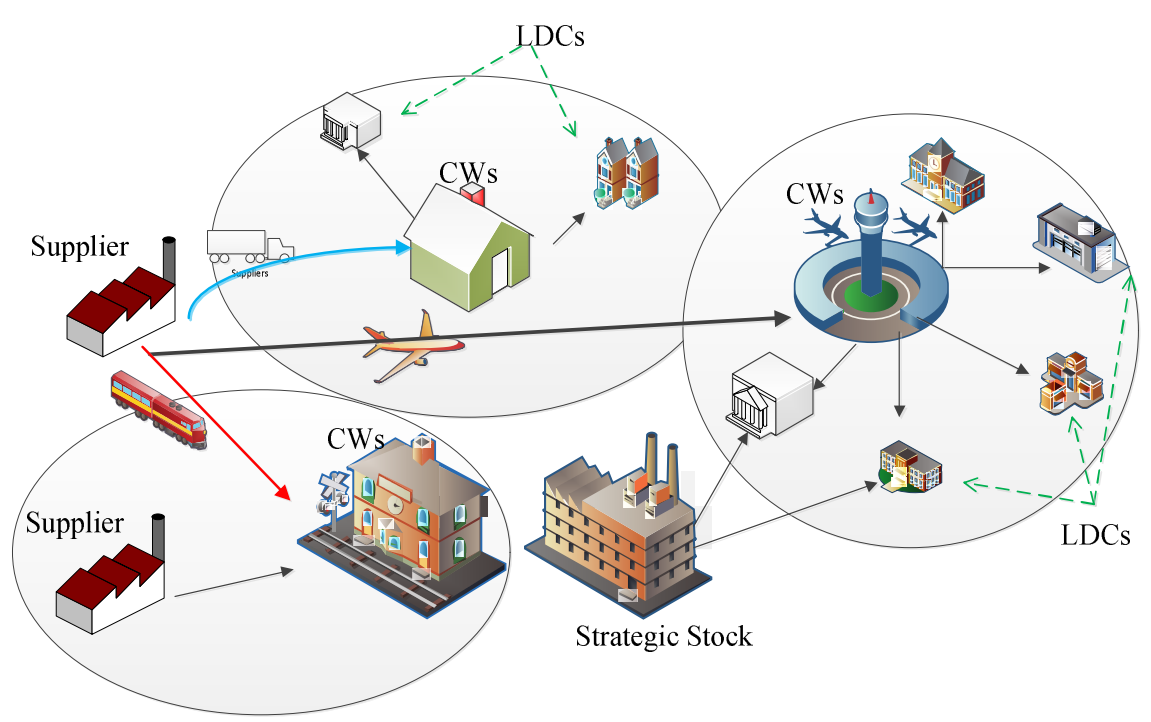

Fig. 2. Overall structure of HRC (Nezhadroshan et al. 2020).

\subsection{Resilience parameter}

Here, we consider resilience measure by determining facility's resilience level (Suppliers, LDCs, and CWs). Table 2 indicates the focus of literature in each criterion. 
Table 2. Provides these means with their helpful references for each one

\begin{tabular}{|c|c|c|c|c|c|c|c|c|c|c|c|c|c|c|c|c|}
\hline \multicolumn{17}{|c|}{$\begin{array}{l}\text { No. } \\
\text { Criteria }\end{array}$} \\
\hline $\mathrm{C}_{1}$ & $\begin{array}{l}\text { Interchangeable } \\
\text { people }\end{array}$ & $x$ & $x$ & $x$ & $x$ & $x$ & $x$ & $x$ & $x$ & & & & & & & \\
\hline $\mathrm{C}_{2}$ & Flexible facilities & $x$ & $x$ & $x$ & $x$ & & & & $x$ & $x$ & $x$ & & & & & \\
\hline $\mathrm{C}_{3}$ & $\begin{array}{l}\text { Profound relation } \\
\text { with major suppliers }\end{array}$ & $x$ & $x$ & $x$ & & $x$ & & & & & & & & & & \\
\hline $\mathrm{C}_{4}$ & $\begin{array}{l}\text { Distributed power, } \\
\text { enabled to take } \\
\text { needed measures }\end{array}$ & $x$ & $x$ & $x$ & $x$ & $x$ & $x$ & $x$ & $x$ & & & $x$ & $x$ & & & \\
\hline $\mathrm{C}_{5}$ & $\begin{array}{l}\text { Continued } \\
\text { Communication } \\
\text { amongst well- } \\
\text { informed employees }\end{array}$ & $x$ & $x$ & $x$ & $x$ & $x$ & $x$ & $x$ & $x$ & & & $x$ & $x$ & & & \\
\hline $\mathrm{C}_{6}$ & $\begin{array}{l}\text { Information-sharing } \\
\text { with suppliers and } \\
\text { customers }\end{array}$ & & & $x$ & & $\times$ & $x$ & $x$ & & $x$ & $x$ & $x$ & $x$ & $x$ & & \\
\hline $\mathrm{C}_{7}$ & $\begin{array}{l}\text { Auto-ID technology } \\
\text { such as RFID }\end{array}$ & $x$ & $x$ & & & $x$ & $x$ & $x$ & & $x$ & & $x$ & $x$ & $x$ & $x$ & $x$ \\
\hline $\mathrm{C}_{8}$ & Process improvement & $x$ & $x$ & $x$ & $\times$ & & $\times$ & $\times$ & & & & $x$ & $\times$ & & & \\
\hline
\end{tabular}

203 Source: (Pettit et al. 2010; Tang 2006; Pettit et al. 2013).

\subsection{Modelling}

206 Here, the main assumptions are provided, and then using them and a description of model notations, the 207 proposed bi-objective resilience HRC model is formulated. The main utilized components and assumptions to 208 formulate the resilience HRC model are reported as below.

$209 \checkmark$ Sometimes, a disaster may lead to the destruction of facilities and disturbances in the routes. Therefore,

210 these can cause a disruption in the ability of candidate CWs and suppliers. To this end, the facilities

211 damages are considered by combining different consumable inventory ratios to deal with supply

212 uncertainty.

$213 \checkmark$ Each CW is provided by suppliers (with limited capacity).

$214 \checkmark$ LDCs are provided by either CWs or multiple CWs or strategic stocks.

$215 \checkmark$ Strategic stock is placed in a secure location and beyond the anticipated disaster areas.

$216 \checkmark$ Each strategic stock ships the things immediately, not to all the LDCs, yet most proximate ones.

$217 \checkmark$ Transportation among suppliers and CWs or strategic stock and LDCs is thought multi-mode (Truck,

218 Motorcycle, Helicopter, Train, and Plane).

$219 \checkmark \quad$ The level of resiliency is measured for each facility.

$220 \checkmark$ The various disasters or following minor disasters are thought for modeling. 
$\checkmark$ There are several essential relief commodities that must be distributed. Therefore, to distribute these, various costs are raised associated with shipping, procurement, and inventory.

$\checkmark$ Each supplier and LDC is able to deliver a provided number of relief commodities, and it is on the basis of suppliers' flexibility level. Based on several effective factors such as the impact of the disaster, and the designed scenarios, some parameters are assumed uncertain (e.g., transportation time, demand, cost, etc.).

$\checkmark$ Here, we consider several capacity levels for which potential CW which suitable capacity must be identified.

228 Based on the aforementioned assumptions, the following components are utilized in developing proposed resilient HRC model.

$230 \quad$ 3.2.1. Indices

$l \quad$ Potential suppliers, $l=1,2,3, \ldots, L$

$i \quad$ Candidate CWs, $i=1,2,3, \ldots, I$

$j \quad$ Candidate LDCs, $j=1,2,3, \ldots, J$

$k \quad$ Demand zones, $k=1,2,3, \ldots, K$

$h \quad$ Potential strategic stocks, $h=1,2,3, \ldots, H$

$m \quad$ Potential transportation mode, $m=1,2,3, \ldots, M$

$S \quad$ Potential disaster scenarios, $s=1,2,3, \ldots, S$

$q \quad$ Relief commodities, $q=1,2,3, \ldots, Q$

c Capacity levels of CWs, $c=1,2,3, \ldots, C$

$g \quad$ Potential sub-sequent disasters, $g=1,2,3, \ldots, G$

\subsubsection{Parameters}

$F_{i}^{c} \quad$ Cost of creating ith $\mathrm{CW}$ at capacity level c

$G_{j} \quad$ Cost of creating jth LDC

$E_{h} \quad$ Cost of creating hth strategic stocks

$I H_{q} \quad$ Inventory saving cost of item q

$U C_{q}^{i} \quad$ Unit inventory cost of unused item q at each CWs i

$U L_{q}^{j} \quad$ Unit inventory cost of unused item q at each LDCs j

$\lambda_{q}^{i} \quad$ Consumable rate of inventory for item $\mathrm{q}$ at $\mathrm{CW} \mathrm{i}$

$\mu_{q}^{j} \quad$ Consumable rate of inventory for item q at LDC $\mathrm{j}$

$\xi_{l} \quad$ Consumable rate of capacity for supplier 1

$U S_{q} \quad$ Shortage cost for each unit of commodity q 
$\zeta_{i j m} \quad 1$, if mode $\mathrm{m}$ is available between the ith $\mathrm{CW}$ and $\mathrm{jth} \mathrm{LDC} ; 0$ otherwise

$\omega_{\text {lim }} \quad 1$, if mode $\mathrm{m}$ is available between the lth supplier and ith $\mathrm{CW} ; 0$ otherwise

$D_{q k} \quad$ Demand of the commodity q by demand zone k

$V^{c} \quad$ Storing capacity of the established CW at capacity level c

$C A_{j} \quad$ Storing capacity of the $\mathrm{LDC} \mathrm{j}$

$S A_{h}^{q} \quad$ Storage capacity of the hth strategic stock for qth item

$C S_{q l} \quad$ Storage capacity of the lth supplier for the qth item

$C A P_{i j m} \quad$ Capacity of shipping approach between ith $\mathrm{CW}$ and jth LDC by mode $\mathrm{m}$

$C C P_{\text {lim }} \quad$ Capacity of shipping approach between the supplier 1 and the $\mathrm{CW} \mathrm{i}$ by mode $\mathrm{m}$

$C T_{\text {qlim }} \quad$ Cost of transportation mode between the lth supplier and the ith $\mathrm{CW}$ via mode m for qth item

$C T R_{\text {qijkm }}$ Cost of transportation mode between ith $\mathrm{CW}$ and jth LDC to demand point $\mathrm{k}$ via mode $\mathrm{m}$ for qth item

$A_{q} \quad$ Needed unit storing capacity of the commodity q

$P_{s} \quad$ Possibility of occurring the scenario s

$\alpha_{i} \quad$ Resiliency level of the ith CWs

$\theta_{j} \quad$ Resiliency level of the jth LDCs

$\phi \quad$ Sub-sequent disasters effects on demands after the major disaster ( $\mathrm{g}$ is the number of minor disasters)

$\rho_{q l} \quad 1$, if supplier lth capable to deliver qth item

$C a p l_{\max } \quad$ Maximum deprivation capacity levels so that there are no life losses.

$\psi_{k} \quad$ Deprivation cost function, which depends on the deprivation capacity levels in demand zones, $\mathrm{K}$ BigM upper bound demand

\subsubsection{Decision variables}

$Y_{i}^{c} \quad=1$, when the nominee $\mathrm{CW}$ i is established at capacity level $\mathrm{c}$; otherwise $=0$

$O_{j} \quad=1$, when the nominee LDC $\mathrm{j}$ is established; otherwise $=0$

$\gamma_{h} \quad=1$, if the hth candidate strategic stock is opened; 0 , otherwise

$\tau_{l} \quad=1$, if the lth candidate supplier is selected; 0 , otherwise 


\begin{tabular}{|c|c|}
\hline$R_{q i}$ & The amount of inventoried part $\mathrm{q}$ in the $\mathrm{CW} \mathrm{i}$ \\
\hline$U_{q j}$ & The amount of inventoried part $\mathrm{q}$ in the $\mathrm{LDC} \mathrm{j}$ \\
\hline$U I_{q i}$ & The amount of unused inventoried part $\mathrm{q}$ in the $\mathrm{CW} \mathrm{i}$ \\
\hline$U R_{q j}$ & The amount of unused inventoried part $q$ in the LDC $j$ \\
\hline$N_{i j m}$ & $=1$, if shipping type $\mathrm{m}$ is selected between ith $\mathrm{CW}$ and jth LDC \\
\hline$C_{\text {lim }}$ & $=1$, if shipping type $\mathrm{m}$ is selected between lth supplier and ith $\mathrm{CW}$ \\
\hline$x_{q j k}$ & Amount of the distributed part $\mathrm{q}$ from the $\mathrm{LDC} \mathrm{j}$ to demand zone $\mathrm{k}$ \\
\hline$z_{q i j k m}$ & Amount of the shipped part $\mathrm{q}$ from the $\mathrm{CW} i$ to demand zone $\mathrm{k}$ via LDC $\mathrm{j}$ and transportation mode $\mathrm{m}$ \\
\hline$v_{q h j k}$ & Amount of the shipped part $\mathrm{q}$ from the strategic stock $\mathrm{h}$ to demand zone $\mathrm{k}$ via LDC $\mathrm{j}$ \\
\hline$w_{\text {qlim }}$ & Amount of the shipped part $\mathrm{q}$ from the supplier 1 to the $\mathrm{CW}$ i via transportation mode $\mathrm{m}$ \\
\hline$\eta_{q k}$ & Amount of the unsatisfied demand part $\mathrm{q}$ in demand zone $\mathrm{k}$ \\
\hline
\end{tabular}

$$
\begin{aligned}
& \operatorname{Min} T C=\sum_{i} \sum_{c} F_{i}^{c} \cdot Y_{i}^{c}+\sum_{j} G_{j} \cdot O_{j}+\sum_{h} E_{h} \cdot \gamma_{h}+\sum_{q} \sum_{k} \sum_{i} I H_{q} \cdot R_{k i} \\
& +\sum_{q} \sum_{k} \sum_{j} I H_{q} \cdot U_{k j}+\sum_{q} \sum_{i} U C_{q}^{i} \cdot U I_{q i}+\sum_{q} \sum_{j} U L_{q}^{j} \cdot U R_{q j} \\
& +\sum_{q} \sum_{k} U S_{q} \cdot \eta_{q k}+\sum_{q} \sum_{l} \sum_{i} \sum_{m} C T_{q l i m} \cdot w_{q l i m} \\
& +\sum_{q} \sum_{i} \sum_{j} \sum_{k} \sum_{m} C T R_{q i j k m} \cdot z_{q i j k m}+\sum_{q} \sum_{i} \sum_{j} \sum_{k} \sum_{m} \psi\left(C A P_{i j m}\right) \cdot z_{q i j k m} \cdot N_{i j m} \\
& +\sum_{q} \sum_{l} \sum_{i} \sum_{m} \psi\left(C C P_{l i m}\right) \cdot w_{q l i m} \cdot C_{l i m} \\
& \operatorname{Max}=\sum_{i} \sum_{c} \alpha_{i} \cdot Y_{i}^{c}+\sum_{j} O_{j} \cdot \theta_{j}
\end{aligned}
$$

238 Subject to:

$$
\begin{array}{ll}
\sum_{q} A_{q} \cdot R_{q i} \leq \sum_{c} V^{c} . Y_{i}^{c} & \forall i \in I \\
\sum_{c} Y_{i}^{c} \leq 1 & \forall i \in I \\
\sum_{q} A_{q} \cdot U_{q j} \leq C A_{j} \cdot O_{j} & \forall j \in J \\
\sum_{j} x_{q j k}+\sum_{i} \sum_{j} \sum_{m} z_{q i j k m}+\sum_{h} \sum_{j} v_{q h j k}=D_{q k} \sum_{g}\left(1+\phi_{g}\right)-\eta_{q k} \quad \forall k \in K, q \in Q
\end{array}
$$




$$
\begin{array}{lc}
\sum_{k} x_{q j k}+U R_{q j}=\mu_{q s}^{j} \cdot U_{q j} & \forall j \in J, q \in Q \\
\sum_{j} \sum_{k} \sum_{m} z_{q i j k m}+U I_{q i}=\lambda_{q s}^{i} \cdot R_{q i} & \forall i \in I, q \in Q \\
\sum_{q} \sum_{k} z_{q i j k m} \leq \zeta_{i j m} \cdot C A P_{i j m} \cdot N_{i j m m} & \forall i \in I, j \in J, m \in M \\
\sum_{i} \sum_{m} w_{q l i m} \leq \rho_{q l} \cdot \xi_{l} \cdot C S_{q l} \cdot \tau_{l} & \forall q \in Q, l \in L \\
\sum_{q} w_{q l i m} \leq \omega_{l i m} \cdot C C P_{l i m} \cdot C_{l i m} & \forall l \in L, i \in I, m \in M \\
\sum_{k} \sum_{j} v_{q h j k} \leq S A_{h}^{q} \cdot \gamma_{h} & \forall h \in H, q \in Q \\
w_{q l i m} \leq M \cdot C_{l i m} \cdot \omega_{l i m} & \forall l \in L, i \in I, m \in M, q \in Q \\
z_{q i j k m} \leq M \cdot N_{i j m} \cdot \zeta_{i j m} & \forall j \in J, j \in J, i \in I, m \in M, q \in Q \\
C A P_{i j m} \cdot N_{i j m} \leq C a p l_{\max } & \forall l \in L, i \in I, m \in M \\
C C P_{l i m} \cdot C_{l i m} \leq C a p l_{\max } & \forall i \in I, l \in L, m \in M, c \in C, j \in J, h \in H \\
z_{q i j k m}, x_{q j k}, \eta_{q k}, w_{q l i m}, v_{q h j k}, U R_{q j}, U_{q j}, R_{q i}, U I_{q i} \geq 0 \\
\forall i \in I, j \in J, l \in L, k \in K, h \in H, q \in Q \\
O_{j}, Y_{i}^{c}, \tau_{l}, \gamma_{h}, N_{i j m}, C_{l i m} \in\{0,1\}
\end{array}
$$

240 The objective function (1) efforts to minimize the total operational and holding costs of chosen CWs and LDCs.

241 The part two of objective function (1) minimized the shortage cost of unsatisfied demands and cost of unused inventories and transportation cost of items. The last part of objective function (1) minimized the deprivation costs. Objective function (2) seeks to maximize the weighted resilience level of each facility, CW/LDC.

244 Constraint (4) execute limitation on the accessible capacity of CWs. Constraint (5) shows that the maximum one

245 CW with a determined capacity level should be opened in any nominated location. Constraint (6) enforces 246 limitations on the accessible capacity of LDCs. Constraint (7) defines the unfavorable demands for critical items. The right hand of equation (7), defines first demand as well as demands added after sub-sequent minor disasters. Constraints (8) and (9) certify that the transferred amount of each commodity plus its unused inventoried quantity is equal to their related inventory levels for each CW/LDCs. Constraint (10) shows boundaries on the accessible capacity of the transportation system between pairs of CW/LDCs. Constraint (11) imposes limits over the suppliers' available capacity. Each supplier can transfer a specific number or set of critical items which is dependent upon suppliers' flexibility level.

253 Furthermore, each supplier might lose its capacity partially or totally, and constraint right hand (11) ensures these circumstances. Constraint (12) guarantees confines on the available transportation system capacity between pair of supplier/CWs. Constraint (13) imposes limits on the available capacity strategic stock. Constraints (14) and (15) guarantee that the quantity of each item will be shipped if the transportation system is 
available. Constraints (16) and (17) guarantee that the Capacity of shipping from either the between CW and LDC or supplier to the $\mathrm{CW}$ is less than or at most equal to a maximum deprivation capacity level so that there are no life losses. Constraint (18) and (19) determine the type of decision variables.

\subsection{Model Linearization}

According to Section 3.3, the multiplication of a binary variable with a continuous variable in objective one has led to the proposed model being nonlinear. Using the change of the traditional variable, the proposed model turns into a linear model to solve this problem. Hence, the constraint of linearization is defined for each variable as follows: Gholizadeh et al. (2020):

$$
\begin{array}{ll}
\sum_{q} \sum_{k} z_{q i j k m} \leq N_{i j m} . B i g M & \forall j \in J, i \in I, m \in M \\
\sum_{q} \sum_{k} H H_{q i j k m} \leq \sum_{q} \sum_{k} Z_{q i j k m} & \forall j \in J, i \in I, m \in M \\
\sum_{q} \sum_{k} H H_{q i j k m} \geq \sum_{q} \sum_{k} Z_{q i j k m}-\left(1-N_{i j m}\right) * B i g M & \forall j \in J, i \in I, m \in M
\end{array}
$$

266 For the last statement of the objective function 1, we do the same.

\subsection{Proposed robust optimization model}

269 This section considers a heuristic solution for a sustainable supply and delivery model with respect to uncertainty data. Since the computational time for each model MILNP and MILP increases with increasing variables and levels of uncertainty. This has caused the model to be unacceptable at some time.

272 Therefore, we need an innovative method based on the binaries variable refinement that is the nonlinear factor of the proposed model. Proposed discoveries were tested for all samples of medium and large experiments, including large data, used for MINLP and MILP. The suggested heuristics are shown in the flowchart below

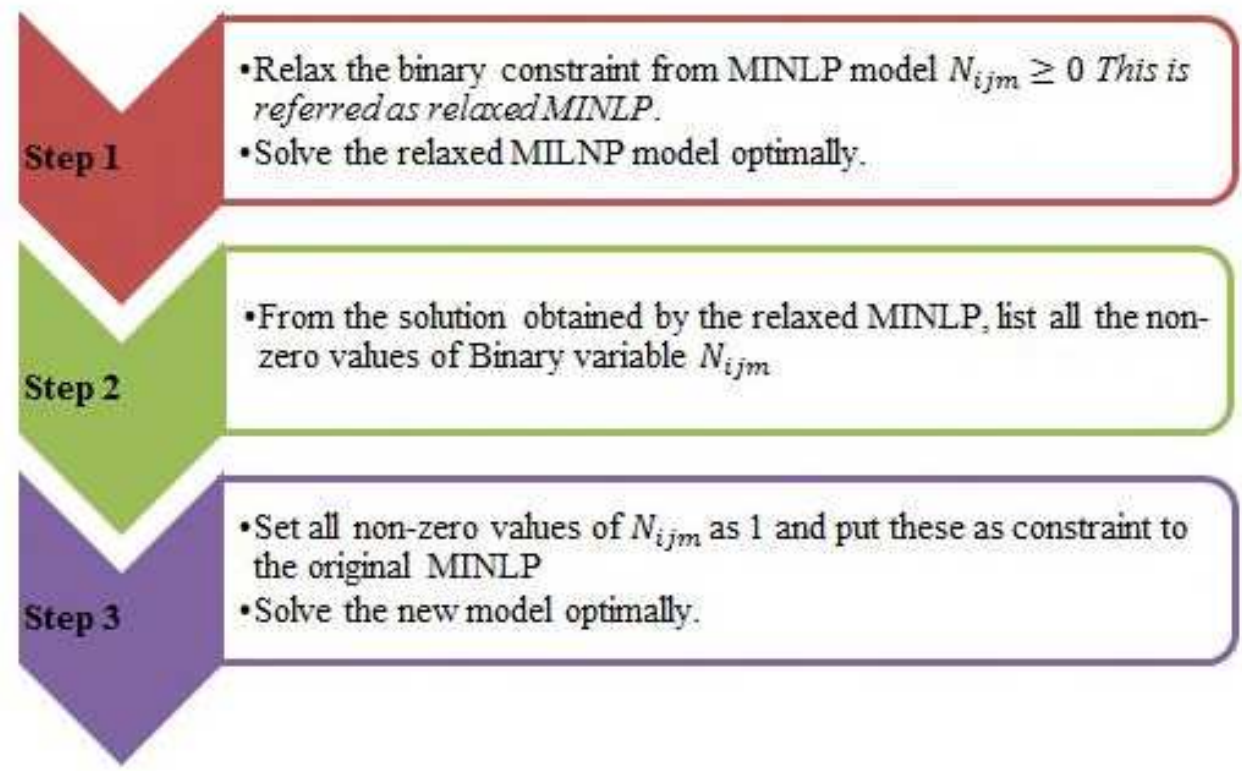

Fig. 3. steps for proposed heuristics 
279 In order to solve optimization problems with data uncertainty, a robust technique was put forward in the early

2801970 s and has lately been widely studied and developed. Under this approach tends to adopt an optimal answer to the nominal values of data to ensure that the justified and optimal response when the data is changed is guaranteed (Gholizadeh et al. 2020).

283 In the robust optimization model, there are two types of variables: design variables and control variables. Design 284 variables have been decided before the potential parameters are realized and cannot be adjusted after realization. Time control variables are subject to tuning to trigger a particular occurrence of potential parameters.

$286 \mathrm{x}$ vector of design variables and $\mathrm{y}$ vector of control variables. A, B and C are the parameter coefficients, $\mathrm{b}$ and $\mathrm{e}$ 287 are the parameter vectors (right side values). A and b are certain values; While B, C and e are uncertain. A 288 special understanding of the parameter is called the uncertainty of the scenario, which is assigned s symbol and its probability is determined byp ${ }_{s}$. The $\Omega$ symbol is used to represent a set of scenarios. The coefficients of uncertainty are $e_{s}$ and $C_{s}$ ' $B_{s}$ for each scenarios $\in \Omega$. Also, the control variable $y$ is modified after understanding the scenario; it can be assigned the $\mathrm{y}_{\mathrm{s}}$ the symbol for the scenario s. Because of the uncertainty of the parameters, the model may not be justified for a number of scenarios. Because of the uncertainty of the parameters, the model may not be justified for a number of scenarios; therefore, $\eta_{s}$ show the models unjustified ness under any scenario $s$. If the model is justified, $\eta_{s}$ is equal to zero; otherwise, it will receive a positive result from the following equations. The model is based on the method of (Mulvey et al. 1995) as follows:

$\operatorname{Min} \sigma\left(x, y_{1}, y_{2}, \ldots, y_{s}\right)+\gamma \rho\left(\eta_{1}, \eta_{2}, \ldots, \eta_{s}\right)$

S.t.

$$
\begin{aligned}
& A x=B, \\
& B_{S} x+C_{S} y_{S}+\eta_{S}=e_{S}, \\
& x \geq 0, y_{S} \geq 0, \eta_{S} \geq 0, \forall s \in \Omega .
\end{aligned}
$$

297 There can be observed 2 parts in the objective function above: the first is a steady-state solution and shows the second equilibrium of the model by weight $\gamma$. The following two terms are discussed below for the Array of $\mathrm{f}(\mathrm{x}, \mathrm{y})$ the symbol $\xi$, which is a cost and utility function, is used. And for each scenario $\xi_{s}=f\left(x, y_{s}\right)$ the high variance for $\xi_{\mathrm{s}}=\mathrm{f}\left(\mathrm{x}, \mathrm{y}_{\mathrm{s}}\right)$ indicates that the decision has a high risk. In other words, a small change in the parameters with uncertainty can lead to large changes in the value of the function of measurement. Mulvey et al. (1995) used the following to illuminate the stability of solution $\delta$ is the weight assigned to the solution variance.

$$
\sigma(\mathrm{o})=\sum_{s \in \Omega} p_{S} \xi_{S}+\delta \sum_{s \in \Omega} p_{S}\left(\xi_{S}-\sum_{s \in \Omega} p_{S}{ }^{\prime} \xi_{S}{ }^{\prime}\right)^{2}
$$


303 As you can see a second-order phrase $\sum_{s \in \Omega} p_{S}\left(\xi_{S}-\sum_{s \in \Omega} p_{S}{ }^{\prime} \xi_{S}{ }^{\prime}\right)^{2}$ there is in the phrase. Yu,C.S. et al. (2000)

304 use a value of absolute deflection to use a second-order expression to reduce the operation of the computer time 305 for solving the problem, as shown below:

$$
\sigma(\mathrm{o})=\sum_{s \in \Omega} p_{S} \xi_{S}+\delta \sum_{s \in \Omega} p_{S}\left|\xi_{S}-\sum_{s \in \Omega} p_{S}^{\prime} \xi_{S}^{\prime}\right|
$$

307 Although the above equation contains absolute values, however, two additional variables $\mathrm{Q}_{s}^{+}$and $\mathrm{Q}_{\mathrm{s}}^{-}$can be 308 used to linear the objective function.

309 If $\sum_{s \in \Omega} p_{S}{ }^{\prime} \xi_{S}{ }^{\prime}$ it is more than $\xi_{s}, Q_{s}^{-}$it is interpreted, whereas $Q_{s}^{+}$is equal to $\sum_{s \in \Omega} p_{S}{ }^{\prime} \xi_{S}{ }^{\prime}$ the value smaller than $310 \xi_{S}$. The formulation above changes as follows:

$$
\begin{array}{ll}
\sigma(\mathrm{o})= & \sum_{s \in \Omega} p_{S} \xi_{S}+\delta \sum_{s \in \Omega} p_{S}\left(Q_{s}^{+}+Q_{s}^{-}\right) \\
\text {s.t. } & \\
& \xi_{S}-\sum_{s \in \Omega} p_{S}{ }^{\prime} \xi_{S}^{\prime}=Q_{s}^{+}+Q_{s}^{-}, s \in \Omega, \\
& Q_{s}^{+}, Q_{s}^{-} \geq 0, s \in \Omega .
\end{array}
$$

311 According to the linear programming theory, it is clear that one of the values of $Q_{s}^{+}$and $Q_{s}^{-}$is always zero for

$312 \delta \geq 0$ (Maharjan and Hanaoka 2017). Notice what it $\left|\xi_{S}-\sum_{s \in \Omega} p_{S}{ }^{\prime} \xi_{S}^{\prime}\right|=\left(Q_{s}^{+}+Q_{s}^{-}\right)$is.

313 The second phrase above objective function $\gamma \rho\left(\eta_{1}, \eta_{2}, \ldots, \eta_{s}\right)$ that is for being unjustified the model is used and 314 shows the stability of the model. They weight is allocated for non-justification and illustrates the cost-benefit 315 analysis between a robust model and a solution. Here, the $\eta_{s}$ an unjustified model shows that for an uncertainty 316 parameter under the scenario s has been created due to capacity constraints. According to the above discussion, the function of the final goal is formulated as follows.

$$
\operatorname{Min} \sum_{s \in \Omega} p_{S} \xi_{S}+\delta \sum_{s \in \Omega} p_{S}\left(Q_{s}^{+}+Q_{s}^{-}\right)+\gamma \sum_{s \in \Omega} p_{S} \eta_{S}
$$

\subsection{Robust model}

320 In this section, owing to the demand uncertainties and cost of deprivation in the proposed model, robust optimization is applied to tackle this issue, as stated in Section 3.5. The robust optimization model of the proposed problem and index and parameters and decision variables of the model is demonstrated below. 


\subsubsection{Index}

Demand and cost of deprivation Scenario (Low, Average, Much) $s=1, \ldots, s$

\subsubsection{Parameters}

$\begin{array}{ll}P_{s} & \text { Probability of scenario } s \\ \omega_{j} & \text { infeasibility weight being set experimentally } j \\ \lambda & \text { The weight of risk }\end{array}$

\subsubsection{Decision variables}

$\theta_{\mathrm{s}} \quad$ The linearization coefficient under the scenario $\mathrm{s}$

$\delta_{\mathrm{s}} \quad$ The surplus variables in the scenario $\mathrm{s}$

$\operatorname{MinZF}=\sum_{\mathrm{s}} \mathrm{P}_{\mathrm{s}} \mathrm{OBJ} 1_{\mathrm{s}}+\lambda \sum_{\mathrm{s}} \mathrm{P}_{\mathrm{s}}\left(\mathrm{OBJ} 1_{\mathrm{s}}-\sum_{\mathrm{s}^{\prime}} \mathrm{P}_{\mathrm{s}^{\prime}} \mathrm{OBJ} 1_{\mathrm{s}^{\prime}}+2 \theta_{\mathrm{s}}\right)+\omega \sum_{\mathrm{s}} \mathrm{P}_{\mathrm{s}} \delta_{\mathrm{s}}$

$\operatorname{MaxRF}=\sum_{\mathrm{s}} \mathrm{P}_{\mathrm{s}} \mathrm{OBJ} 2_{\mathrm{s}}-\lambda \sum_{\mathrm{s}} \mathrm{P}_{\mathrm{s}}\left(\left(\mathrm{OBJ} 2_{\mathrm{s}}-\sum_{\mathrm{s}^{\prime}} \mathrm{P}_{\mathrm{s}^{\prime}} \mathrm{OBJ} 2_{\mathrm{s}^{\prime}}\right)+2 \theta_{\mathrm{s}}\right)$

$\mathrm{OBJ} 1_{\mathrm{s}}-\sum_{\mathrm{s}^{\prime}} \mathrm{P}_{\mathrm{s}^{\prime}} \mathrm{OBJ} 1_{\mathrm{s}^{\prime}}+\theta_{\mathrm{s}} \geq 0 \quad \forall \mathrm{s}$

$\mathrm{OBJ} 2_{\mathrm{s}}-\sum_{\mathrm{s}^{\prime}} \mathrm{P}_{\mathrm{s}^{\prime}} \mathrm{OBJ} 2_{\mathrm{s}^{\prime}}+\theta_{\mathrm{s}} \geq 0 \quad \forall \mathrm{s}$

$\theta_{\mathrm{s}} \geq 0$

The first and second terms in Eqs. (28) and (29) indicated the mean value and objective functions' variance, in turn. The final terming (29) of the objective function is to assess the robustness of the model based on the control constraints' infeasibility values under each scenario. The constraints (31-31) are auxiliary constraints added to the model for linearization. And a constraint (32) is non-negative variables.

\section{Solution approach}

330 At first, the resilience parameters used for second objective are obtained using a strong MCDM approach entitled Best Worst Method (BWM). Moreover, the suggested bi-objective model is including several integer decision variables along with some binary variable which it leads to NP-hardness of it. Due to this concern, exact methods cannot be proper especially for large-size problem. Thus, three well-known metaheuristic algorithms are utilized to discover Pareto solutions. Moreover, metaheuristics procedures are illustrated in the next section.

\subsection{BWM}

Before solving the model, the values of resilience parameters, based on the selected criteria of Table 2 should be obtained. To do this, the BWM as a strong MCDM method is applied. The BWM is developed by Rezaei et al (2015), and ease of procedure and less computational table as two key features of it are reported. Also, several 
340 researchers in various fields, such as (Rezaei et al. 2015) report the efficiency of this method. The main steps of

341 BWM are provided as follows.

343 Step 1. Propose criteria based on the expert opinions $\left\{c_{1}, c_{2} \ldots c_{n}\right\}$.

344 Step 2. Select the worst and the best indicators.

345 Step 3. Find the "Best-to-Others" vector. Do pairwise judgment between the best indicator and other criteria via 346 a number from 1 to 9 as follows:

$A_{B}=\left(a_{B 1}, a_{B 2}, \ldots, a_{B n}\right)$

347 here $a_{B j}$ indicates the dominance of the best indicator $B$ than the indicator $j$, and $a_{B B}=1$.

348 Step 4. Find "Others-to-Worst" vector. Do pairwise judgment between the other indicators and the worst 349 indicator as follows:

$A_{W}=\left(a_{1 W}, a_{2 W}, \ldots, a_{n W}\right)^{T}$

350 here, $\mathrm{a}_{\mathrm{jw}}$ demonstrates the superiority of the criterion $\mathrm{j}$ than the worst indicator $\mathrm{W}$, and $\mathrm{a}_{\mathrm{ww}}=1$.

351

352 Step 5. Compute the optimum values of $\left(\omega_{1}^{*}, \omega_{2}^{*}, \ldots, \omega_{n}^{*}\right)$ using the following optimization problem (Rezaei 353 2015).

354

$$
\begin{aligned}
& \min \xi \\
& \text { s.t. } \\
& \left|\frac{\omega_{j}}{\omega_{W}}-a_{j W}\right| \leq \xi \quad \text { for all } j \\
& \left|\frac{\omega_{B}}{\omega_{j}}-a_{B j}\right| \leq \xi \quad \text { for all } j \\
& \sum_{j} \omega_{j}=1 \\
& \omega_{j} \geq 0 \quad \text { for all } j
\end{aligned}
$$

355 After running the problem (20), the optimum values of $\left(\omega_{1}^{*}, \omega_{2}^{*}, \ldots, \omega_{n}^{*}\right)$ and $\xi^{*}$ are achieved.

356 To calculate the consistency level of the judgments, the value of $\xi^{*}$ and reported consistency index in Table 3 are utilized as equation (21):

$$
\text { Consistency Ratio }=\frac{\xi^{*}}{\text { Consistency Index }}
$$

358

359

Table 3. Information about consistency index (Rezaei 2015)

\begin{tabular}{|l|l|l|l|l|l|l|l|l|l|}
\hline abw & 1 & 2 & 3 & 4 & 5 & 6 & 7 & 8 & 9 \\
\hline Consistency Index & 0.00 & 0.44 & 1.00 & 1.63 & 2.30 & 3.00 & 3.73 & 4.47 & 5.23 \\
\hline
\end{tabular}

Moreover, based on (Rezaei 2015) the final score of alternative i due to the indicators is computed as: 


$$
S^{i}=\sum_{n=1}^{N} \omega_{n} \times C_{i n} \quad \forall i
$$

362 here $\omega_{n}$ represent the final weight of indicator $n, C_{i n}$ is the allocated score of ith supplier based on indicator $n$,

363 and $\mathrm{N}$ shows the number of indicators. Also, the normalized score of suppliers can be formulated as bellow:

$$
\text { Normalized Score }{ }_{k}=\frac{S_{k}}{\sum_{i} S_{i}}
$$

\subsection{Encoding and decoding}

Up to now, various approaches have been proposed to convert mathematical model to a chromosome or solution manner, such as priority-based method and Prufer numbers (Prüfer 1918; Gen et al. 2006). Here, to present the proposed chromosome using the priority-based method, a small-size example is given. In this example, $i=3,1=3$, $\mathrm{h}=2, \mathrm{j}=3, \mathrm{c}=3, \mathrm{q}=2$, and $\mathrm{k}=2$ are supposed. The presented solution matrix has two rows for each item and $(1+2 \mathrm{i}+\mathrm{h}+2 \mathrm{j}+\mathrm{k})$ columns that it has three sections. Fig. 2 shows that all of these sections are consistent with the flows. Moreover, the designed solution matrix is displayed in Fig. 4. In this figure, CL and Pri represents the capacity level and priority, respectively.

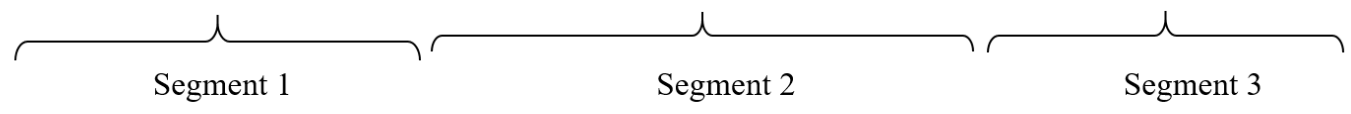

373

374

375

376

377

378

379

380

\begin{tabular}{|c|c|c|c|c|c|c|c|c|c|c|c|c|c|c|c|c|c|c|c|c|}
\hline Ite & no & \multicolumn{3}{|c|}{1} & \multicolumn{3}{|c|}{$\mathrm{i}$} & \multicolumn{5}{|c|}{$\mathrm{h}+\mathrm{i}$} & \multicolumn{3}{|c|}{$\mathrm{j}$} & \multicolumn{3}{|c|}{$\mathrm{j}$} & \multicolumn{2}{|c|}{$\mathrm{k}$} \\
\hline \multirow[b]{2}{*}{1} & Pri & ô. & $\stackrel{m}{\circ}$ & $\stackrel{\infty}{\stackrel{\infty}{0}}$ & $\stackrel{n}{o}$ & $\stackrel{a}{0}$ & $\begin{array}{l}\vec{J} \\
\dot{0}\end{array}$ & $\begin{array}{c}\infty \\
\stackrel{m}{0} \\
0\end{array}$ & $\begin{array}{l}n \\
0 \\
0\end{array}$ & $\begin{array}{l}\infty \\
0 \\
0\end{array}$ & $\begin{array}{l}\hat{\sigma} \\
0\end{array}$ & $\overrightarrow{0}$ & $\stackrel{\varpi}{\sim}$ & $\stackrel{1}{\stackrel{0}{0}}$ & $\stackrel{q}{\stackrel{f}{0}}$ & $\begin{array}{l}\infty \\
\stackrel{0}{0}\end{array}$ & $\overrightarrow{\widetilde{o}}$ & $\tilde{n}$ & $\begin{array}{l}1 \\
0 \\
0\end{array}$ & ڤ్ \\
\hline & $\begin{array}{l}\mathrm{C} \\
\mathrm{L}\end{array}$ & 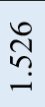 & 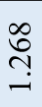 & ஓి & $\begin{array}{l}\text { రె } \\
\stackrel{n}{-}\end{array}$ & $\frac{\overparen{N}}{\stackrel{\sim}{\sim}}$ & 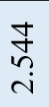 & $\frac{\infty}{\stackrel{\infty}{r}}$ & 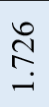 & $\begin{array}{l}\stackrel{m}{\infty} \\
\stackrel{\sim}{i}\end{array}$ & $\begin{array}{l}\stackrel{0}{0} \\
\infty \\
\stackrel{-}{0}\end{array}$ & $\begin{array}{l}\infty \\
\stackrel{\infty}{ٍ} \\
=\end{array}$ & $\begin{array}{l}\text { oे } \\
\stackrel{+}{+}\end{array}$ & $\begin{array}{l}2 \\
\infty \\
\text { ஸे }\end{array}$ & $\stackrel{0}{\underset{r}{ت}}$ & 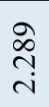 & ને & $\begin{array}{l}\hat{n} \\
\stackrel{\sim}{i}\end{array}$ & $\underset{\sim}{\stackrel{\sim}{\sim}}$ & 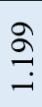 \\
\hline \multirow[b]{2}{*}{2} & Pri & ○े & $\stackrel{m}{m}$ & $\stackrel{\leftrightarrow}{0}$ & 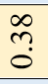 & $\stackrel{m}{m}$ & $\stackrel{\overbrace{}}{\stackrel{9}{0}}$ & ڤे & $\stackrel{n}{m}$ & 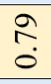 & $\vec{m}$ & $\begin{array}{l}n \\
\infty \\
0\end{array}$ & ñ? & ले & $\stackrel{\infty}{\infty}$ & 广ே. & ஸे & $\begin{array}{l}\infty \\
0 \\
0\end{array}$ & ণั) & 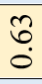 \\
\hline & $\begin{array}{l}\mathrm{C} \\
\mathrm{L}\end{array}$ & $\begin{array}{l}\infty \\
\stackrel{m}{\sim} \\
\stackrel{\sim}{i}\end{array}$ & 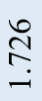 & $\begin{array}{l}\stackrel{\infty}{\infty} \\
\stackrel{\infty}{i}\end{array}$ & $\begin{array}{l}\stackrel{0}{0} \\
\infty \\
\stackrel{\infty}{0}\end{array}$ & $\begin{array}{l}\infty \\
\stackrel{0}{\rightleftarrows}\end{array}$ & $\begin{array}{l}8 \\
\text { ๖े } \\
\text {. }\end{array}$ & $\begin{array}{l}\stackrel{\infty}{ } \\
\stackrel{\text {, }}{\text { in }}\end{array}$ & 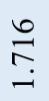 & $\begin{array}{l}\stackrel{2}{\infty} \\
\stackrel{+}{i}\end{array}$ & กิ & $\begin{array}{l}\hat{n} \\
\stackrel{+}{\sim}\end{array}$ & 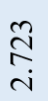 & $\stackrel{\text { gे }}{=}$ & $\begin{array}{l}\stackrel{0}{\sim} \\
\text { ก̦ } \\
-\end{array}$ & $\begin{array}{l}\infty \\
\stackrel{0}{0} \\
\end{array}$ & 오 & $\begin{array}{l}\text { రె } \\
n \\
\end{array}$ & $\underset{\stackrel{\sim}{\sim}}{\stackrel{\overbrace{}}{\sim}}$ & $\begin{array}{l}\stackrel{J}{+} \\
\stackrel{n}{\sim}\end{array}$ \\
\hline
\end{tabular}

Fig. 4. Design of proposed random key chromosome.

The matrix presented in Fig. 4 is created randomly and all genes of first row of this chromosome are filled by numbers between $[0,1]$, and all genes of second row of this chromosome are filled by uniform [1, c]. After sorting the values of first row and rounding the values of second row, the priority-based matrix is achieved. Also sorting for each sub-section, is performed separately. The design of proposed priority-based chromosome is exposed in Fig. 5. 


\begin{tabular}{|c|c|c|c|c|c|c|c|c|c|c|c|c|c|c|c|c|c|c|c|c|}
\hline Item & node & \multicolumn{3}{|c|}{1} & \multicolumn{3}{|c|}{$\mathrm{i}$} & \multicolumn{5}{|c|}{$\mathrm{h}+\mathrm{i}$} & \multicolumn{3}{|c|}{$\mathrm{j}$} & \multicolumn{3}{|c|}{$\mathrm{j}$} & \multicolumn{2}{|c|}{$\mathrm{k}$} \\
\hline \multirow{2}{*}{1} & Pri & 1 & 2 & 3 & 3 & 2 & 1 & 2 & 3 & 5 & 4 & 1 & 2 & 1 & 3 & 3 & 1 & 2 & 1 & 2 \\
\hline & $\mathrm{CL}$ & - & - & - & 2 & 2 & 3 & - & - & 3 & 2 & 1 & - & - & - & - & - & - & - & - \\
\hline \multirow{2}{*}{2} & Pri & 3 & 2 & 1 & 2 & 1 & 3 & 5 & 2 & 3 & 1 & 4 & 3 & 2 & 1 & 2 & 1 & 3 & 1 & 2 \\
\hline & CL & - & - & - & 2 & 1 & 1 & - & - & 2 & 1 & 2 & - & - & - & - & - & - & - & - \\
\hline
\end{tabular}

385 Segment 1 presents the sequence of allocation from suppliers (1) to CWs (i). Segment 2 presents the sequence of allocation from CWs and strategic stocks ( $\mathrm{h}+\mathrm{i})$ to LDCs (j). Also, segment 3 presents the sequence of allocation from LDCs (j) to affected areas (k). Moreover, each CWs (i) capacity level is presented in the second row of the suggested chromosome. Additionally, the allocation procedure is shown in Fig. 6, which can be used from needed steps of each segment.

Fig. 5. Design of proposed priority-based chromosome. 


$$
\begin{aligned}
& \text { For } \mathrm{q}=1 \text { to } \mathrm{Q} \\
& \text { Inputs: } \\
& \begin{array}{ll}
\mathrm{I} \text { : set of source } \\
\mathrm{J} \text { : set of applicant } \\
\\
\mathrm{D}_{\mathrm{j}} \text { : demand of applicant } \mathrm{j} \\
\mathrm{Ca}_{\mathrm{i}} \text { : capacity of source } \mathrm{i} \\
\mathrm{V}(\mathrm{I}+\mathrm{J}) \text { : Encode solution of item } \mathrm{q}
\end{array}
\end{aligned}
$$

Outputs: Xaloc $\mathrm{ij}_{\mathrm{j}}$ : quantity of distribution between nodes

$\mathrm{Y}_{\mathrm{j}}$; binary variable displays the active applicant

$\mathrm{U}_{\text {gi: }}$ amount of unused item q of source $\mathrm{i}$

$\mathrm{U}_{\mathrm{gj}}$ : amount of unused item $\mathrm{q}$ of applicant $\mathrm{j}$

while $\sum_{\mathrm{i}} \mathrm{Ca}_{\mathrm{i}} \geq 0 \& \& \sum_{\mathrm{j}} \mathrm{D}_{\mathrm{j}} \geq 0$

Step1: Xaloc $_{\mathrm{ij}}=0 \forall \mathrm{i} \in \mathrm{I}, \forall \mathrm{j} \in \mathrm{J}$

Step2: select value of first column of sub-segment I for i index select value of first column of sub-segment $\mathrm{J}$ for $\mathrm{j}$ index

Step3: $\operatorname{Xaloc}_{\mathrm{jij}}=\min \left(\mathrm{Ca}_{\mathrm{i}}, \mathrm{D}_{\mathrm{j}}\right)$

Update demands and capacities

$$
\mathrm{Ca}_{\mathrm{i}}=\mathrm{Ca}_{\mathrm{i}}-\text { Xaloc }_{\mathrm{ij}} \quad \mathrm{D}_{\mathrm{j}}=\mathrm{D}_{\mathrm{j}}-\mathrm{Xaloc}_{\mathrm{ij}}
$$

Step4: if $\mathrm{Ca}_{\mathrm{i}}=0$ then $\mathrm{V}(1, \mathrm{I})=0$

$$
\text { if } \mathrm{D}_{\mathrm{i}}=0 \text { then } \mathrm{V}(1, \mathrm{~J})=0
$$

End while

Step5: $\mathrm{U}_{\mathrm{gi}}=\mathrm{Ca}_{\mathrm{i}} \quad \mathrm{U}_{\mathrm{qj}}=\mathrm{D}_{\mathrm{j}}$

Step6: for $\mathrm{j}=1$ to $\mathrm{J}$

$$
\text { if } \sum_{\mathrm{j}} \mathrm{Xaloc}_{\mathrm{ij}}>0 \text { then } \mathrm{Y}_{\mathrm{j}}=1
$$

End for

End for

Fig. 6. The allocation procedure of proposed model.

\subsection{LP-metric method}

The method of LP-metric attempts to lower the objective functions' deviation from its desired solution. That is to say; the most desirable and possible solution is the one that has the shortest distance from the ideal point. In the lp-metric method to measure the proximity of a solution to the ideal solution, metric distance is used. This condition is described as a consistent function.

401 For "the less the better" problems, the compatibility function is defined as follows:

$$
L P=\left[\sum_{i=1}^{n} w_{i}\left(\frac{f_{i}\left(\mathrm{x}_{i}\right)-f_{i}\left(x_{i}^{\min }\right)}{f_{i}\left(\bar{x}_{i}^{\max }\right)-f_{i}\left(x_{i}^{\min }\right)}\right)^{p}\right]^{1 / p}
$$

402 For "the more the better" problems, the compatibility function are defined as follows: 


$$
L P=\left[\sum_{i=1}^{n} w_{i}\left(\frac{f_{i}\left(\mathrm{x}_{i}^{\max }\right)-f_{i}\left(x_{i}\right)}{f_{i}\left(\mathrm{x}_{i}^{\max }\right)-f_{i}\left(x_{i}^{\min }\right)}\right)^{p}\right]^{1 / p}
$$

403 Where $f_{i}\left(\overline{x_{i}^{\max }}\right)$ and $f_{i}\left(\overline{x_{i}^{\min }}\right)$ represent the ideal counter-solution to i-th goal optimization

404 In the above equations $X^{\min }$ and $X^{\max }$ represent the ideal solution in optimizing the objective function i-th and $X_{\mathrm{i}}$ represent the available solution. $\mathrm{w}_{\mathrm{i}}$ denotes the degree of importance for $\mathrm{i}$-th purpose.

$406 \mathrm{P}$ indicates the degree of emphasis on the existing deviations, so the higher the $\mathrm{P}$ value, the greater the emphasis 407 on the largest deviations. The value of $\mathrm{P}$ depends on the decision-makers' opinion and is usually of values of $\left\{P=1, P=2, P=\infty\right.$. Also which $\overline{x_{i}^{\max }}$ and $\overline{x_{i}^{\min }} 2$ represent an ideal solution in optimizing the i-th objective function.

\subsection{GA}

412 One of the solutions to large-scale resilience relief logistic problems is the use of heuristic algorithms such as 413 genetic algorithms, which are used in this section to resolve the suggested large-scale model. Since genetic 414 algorithms are a random search method. Many studies have been used in the field that can be found here (Diabat \& Deskoores 2016; Kannan et al. 2010). The first step in solving a metaheuristics method is to create an appropriate structure for the desired problem (Fathollahi-Fard et al. 2020). In this algorithm, the chromosome comprises three parts representing the LDC-demand zone, CW/LDC and supplier-CW, respectively. The possibility of any chosen chromosome is based on its adaptability value and corresponding indices, and chromosomes with preferable possibilities of greater adaptability are designed; for example, the first part determines the Quantity from each LDC to each demand zone for all relief commodities under scenarios. This operator is a hybrid operator, which consists of three steps. In the initial step, a pair of preferred chromosomes $r$ randomly selects between $\left[\mathrm{k}^{*} \mathrm{~s}, \mathrm{q}(\mathrm{i}+\mathrm{j})\right]$. In the second step, the locality is randomly selected for integration between $[1, \mathrm{q}(\mathrm{i}+\mathrm{j})]$ and $[1, \mathrm{~S}+\mathrm{k}-1]$ along the chromosome strand. Eventually, in step three, the value of the two strings, which is determined based on the location of the merger, is specified. The intersection operator used in this research is shown in Fig. 7. Next, the population is populated with mutation operations. A multi-spot mutation operation is deployed for population resumption. Two rows or two columns are randomly selected so as to mutate in each chromosome portion, and the interstices between them are displaced inverted. In the mutation operator used in this study is shown in Fig. 8.

\begin{tabular}{|c|c|c|c|c|c|c|c|c|c|c|c|c|c|c|c|}
\hline 2 & 4 & 2 & 4 & 1 & 5 & & 0 & 0 & 2 & 4 & 1 & 5 & & & \\
\hline 4 & 2 & 2 & 3 & 5 & 6 & & 0 & 0 & 2 & 3 & 5 & 6 & & & \\
\hline 6 & 2 & 6 & 2 & 3 & 4 & & 0 & 0 & 6 & 2 & 3 & 4 & & & \\
\hline 5 & 4 & 4 & 2 & 3 & 6 & 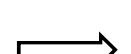 & 0 & 0 & 4 & 2 & 3 & 6 & & & \\
\hline 6 & 2 & 3 & 1 & 4 & 5 & & 6 & 2 & 0 & 0 & 0 & 0 & & & \\
\hline 4 & 2 & 5 & 6 & 2 & 4 & & 4 & 2 & 0 & 0 & 0 & 0 & 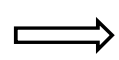 & 24 & $\begin{array}{llll}2 & 4 & 1 & 5\end{array}$ \\
\hline
\end{tabular}




\begin{tabular}{|c|c|c|c|c|c|c|c|c|c|c|c|}
\hline 3 & 1 & 6 & 2 & 3 & 5 & 3 & 1 & 0 & 0 & 0 & 0 \\
\hline 5 & 6 & 5 & 4 & 3 & 6 & 0 & 0 & 5 & 0 & 3 & 0 \\
\hline 2 & 4 & 2 & 1 & 4 & 4 & 2 & 0 & 0 & 0 & 0 & 4 \\
\hline 6 & 5 & 5 & 1 & 2 & 3 & 6 & 0 & 0 & 0 & 0 & 3 \\
\hline 4 & 6 & 3 & 4 & 3 & 2 & 0 & 6 & 0 & 0 & 3 & 0 \\
\hline 4 & 2 & 3 & 4 & 5 & 6 & 4 & 0 & 3 & 4 & 5 & 0 \\
\hline 4 & 2 & 3 & 1 & 3 & 6 & 4 & 0 & 3 & 0 & 3 & 0 \\
\hline 2 & 1 & 2 & 1 & 5 & 5 & 2 & 0 & 2 & 0 & 5 & 5 \\
\hline
\end{tabular}

\begin{tabular}{|ll|llll}
2 & 2 & 2 & 3 & 5 & 6 \\
6 & 1 & 6 & 2 & 3 & 4 \\
5 & 4 & 4 & 2 & 3 & 6 \\
\hline 6 & 2 & 4 & 3 & 4 & 6 \\
4 & 2 & 4 & 3 & 5 & 3 \\
3 & 1 & 2 & 2 & 6 & 5 \\
\hline
\end{tabular}

Fig.7. Crossover operator display

\begin{tabular}{|l|l|l|l|l|l|}
\hline 2 & 4 & 2 & 4 & 1 & 5 \\
4 & 2 & 2 & 3 & 5 & 6 \\
6 & 2 & 6 & 2 & 3 & 4 \\
5 & 4 & 4 & 2 & 3 & 6 \\
6 & 2 & 3 & 1 & 4 & 5 \\
4 & 2 & 5 & 6 & 2 & 4 \\
3 & 1 & 6 & 2 & 3 & 5 \\
\hline
\end{tabular}

$\longrightarrow$\begin{tabular}{|l|l|l|l|l|l|}
\hline 2 & 1 & 2 & 4 & 4 & 5 \\
4 & 5 & 2 & 3 & 2 & 6 \\
6 & 3 & 6 & 2 & 2 & 4 \\
5 & 3 & 4 & 2 & 4 & 6 \\
6 & 4 & 3 & 1 & 2 & 5 \\
4 & 2 & 5 & 6 & 2 & 4 \\
3 & 3 & 6 & 2 & 1 & 5 \\
\hline
\end{tabular}

Fig. 8: mutation operator display

\subsection{Hybrid LP-GA}

In this section, we combine the LP-metric method with a reliable GA to solve multi-objective optimization problems. As mentioned in the previous section, GA is a population-based algorithm that finds the best solution with respect to a target function. However, the proposed model has two objectives, so for each primitive population and the model variables, two variables are considered relevant to the objectives. This method is formulated according to the objective function of the LP-metric method of the GA algorithm. As you know, the objective of LP-metric method is minimization. We can show optimal values for all purposes. The algorithm 


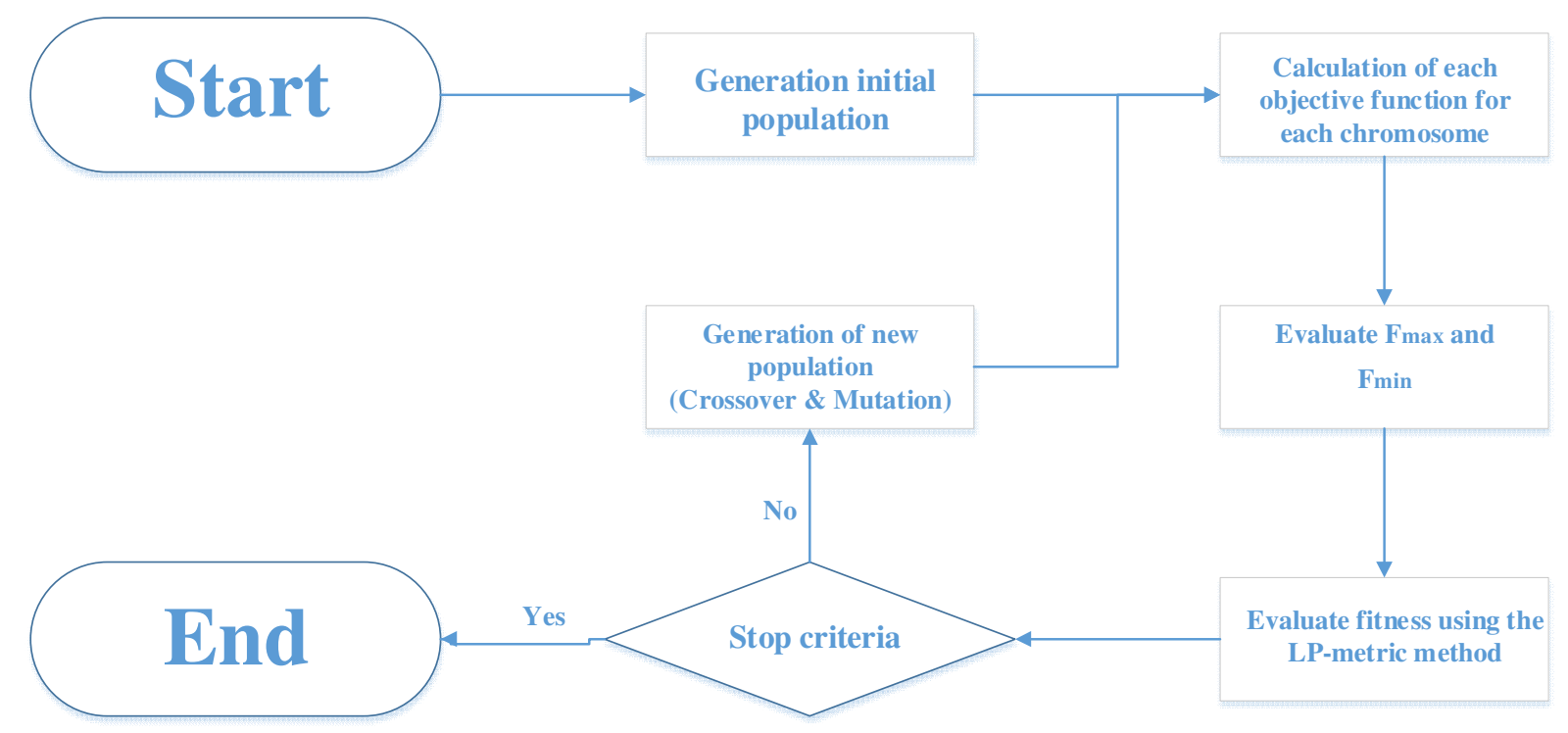

Fig. 9. The steps of the algorithm

452 Here, to set the developed model's parameters, a real case located in Iran is reported. In that regard, the suggested model is used in the survey to show the accuracy and consistency of the outcomes. Indeed, this study is stimulating concerning designing a humanitarian relief chain in Kermanshah province in Iran. Hence, to deals with potential disasters, detailed information about a real disaster case in one of the western provinces of Iran, Kermanshah, is provided. The earthquake's epicenter occurred $17 \mathrm{~km}$ from Sar Pol-e Zahab, $18 \mathrm{~km}$ from the Qasr Shirin and $33 \mathrm{~km}$ from Guilan-e Gharb. And the closest centers of the province to the Ilam earthquake center were with $106 \mathrm{~km}$ and Kermanshah with $127 \mathrm{~km}$ distance.

The province covers a region of $25,009 \mathrm{~km}^{2}$. Furthermore, this province is enriched by many natural resources and it as one of the most thickly populated regions of Iran is raised. The population of the region was 1,945,227 regarding to the census of 2011, in which $46.82 \%$ were the villagers, $53.18 \%$ were related to the urban residents, and rest of them were emigrant. Also, this province is divided into 15 counties and Sari city as its capital is raised as shown in Fig. 10. 


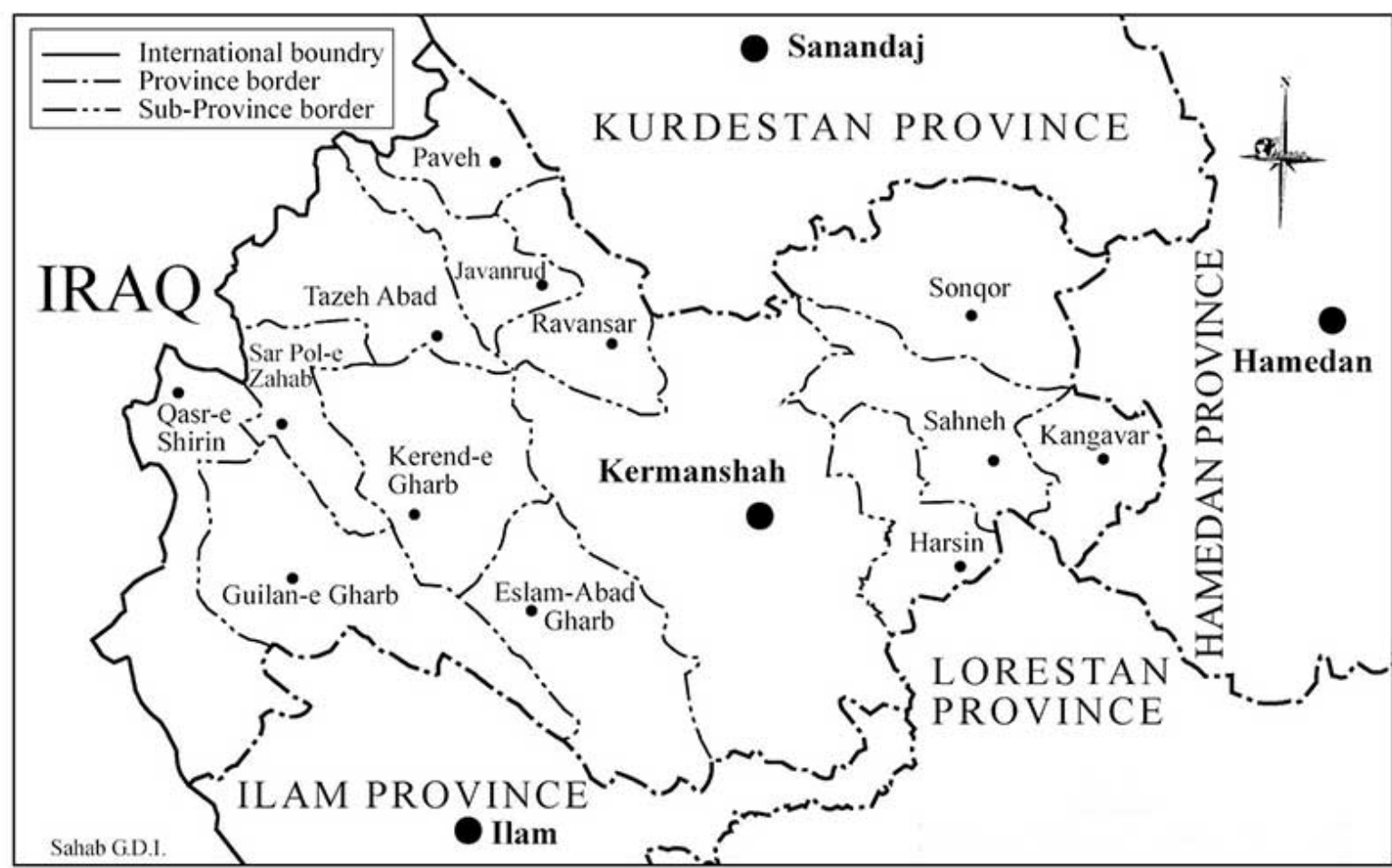

Fig. 10. A schematic map of Kermanshah (adopted from (Wikipedia))

As is clear, the computational time holds a positive association with the number of disruption scenarios, so CPU time will be increased by an increment of the scenarios' numbers. Therefore, three disruption scenarios are considered in our survey. Here, the disaster scenario level dependent upon the occurrence time, and these are exhibited in the Table 4.

Table 4. Different earthquake scenarios' probabilities

\begin{tabular}{|c|c|c|}
\hline Disaster scenarios & Probability & Number \\
\hline Scenario 1 & 0.443 & 3 \\
\hline Scenario 2 & 0.344 & 2 \\
\hline Scenario 3 & 0.213 & 1 \\
\hline
\end{tabular}

Furthermore, to illustrate the effect of increasing the size of the problem on the performance of the solutions and the mathematical model, 10 test problems have been designed in different dimensions in Table 5. Other parameters of proposed model are presented in Table 6-7.

Table 5. The detailed information about the test problems.

\begin{tabular}{|c|c|c|c|c|c|c|c|c|c|c|}
\hline \# of problem & $\mathbf{L}$ & $\mathbf{I}$ & $\mathbf{J}$ & $\mathbf{K}$ & $\mathbf{H}$ & $\mathbf{M}$ & $\mathbf{S}$ & $\mathbf{Q}$ & $\mathbf{C}$ & $\mathbf{G}$ \\
\hline 1 & 3 & 2 & 3 & 2 & 2 & 2 & 3 & 4 & 2 & 1 \\
\hline 2 & 5 & 3 & 5 & 3 & 2 & 3 & 3 & 6 & 3 & 2 \\
\hline 3 & 7 & 4 & 7 & 5 & 3 & 3 & 3 & 9 & 3 & 3 \\
\hline
\end{tabular}




\begin{tabular}{|l|c|c|c|c|c|c|c|c|c|c|}
\hline 4 & 9 & 6 & 9 & 6 & 5 & 3 & 3 & 10 & 5 & 5 \\
\hline 5 & 11 & 7 & 11 & 8 & 6 & 3 & 3 & 15 & 6 & 5 \\
\hline 6 & 12 & 9 & 14 & 10 & 7 & 3 & 3 & 18 & 8 & 6 \\
\hline 7 & 13 & 10 & 16 & 13 & 9 & 3 & 3 & 20 & 10 & 7 \\
\hline 8 & 16 & 12 & 19 & 14 & 10 & 3 & 3 & 22 & 12 & 8 \\
\hline 9 & 17 & 15 & 21 & 18 & 11 & 3 & 3 & 25 & 15 & 9 \\
\hline 10 & 18 & 18 & 23 & 20 & 13 & 3 & 3 & 30 & 20 & 10 \\
\hline
\end{tabular}

481

Table 6. Set values for the rest of the model parameters

\begin{tabular}{|c|c|c|c|c|c|}
\hline Parameter & Values & Unit & Parameter & Values & Unit \\
\hline$F_{i}^{c}$ & $\mathrm{U} \sim[10,16]$ & Billion Rial (BR) & $\omega_{l i m}^{s}$ & 0 or 1 & - \\
\hline$G_{j}$ & $\mathrm{U} \sim[3,6]$ & Billion Rial (BR) & $D_{q k}^{s}$ & $\mathrm{U} \sim[50,300]$ & Set, Kg, Pair, or Box \\
\hline$E_{h}$ & $\mathrm{U} \sim[9,14]$ & Billion Rial (BR) & $V^{c}$ & $\mathrm{U} \sim[80,250]$ & Pallet \\
\hline$I H_{q}$ & $\mathrm{U} \sim[10000,40000]$ & Rial (R) & $C A_{j}$ & $\mathrm{U} \sim[20,100]$ & Pallet \\
\hline$U C_{q}^{i}$ & $\mathrm{U} \sim[10000,35000]$ & Rial (R) & $S A_{h}^{q}$ & $\mathrm{U} \sim[10,150]$ & Pallet \\
\hline$U L_{q}^{j}$ & $\mathrm{U} \sim[10000,35000]$ & Rial (R) & $C S_{q l}$ & $\mathrm{U} \sim[3,10]$ & Pallet \\
\hline$\lambda_{q s}^{i}$ & $\mathrm{U} \sim[0,1]$ & Percentage & $C A P_{i j m}$ & $\mathrm{U} \sim[10,50]$ & Pallet \\
\hline$\mu_{q s}^{j}$ & $\mathrm{U} \sim[0,1]$ & Percentage & $C C P_{\text {lim }}$ & $\mathrm{U} \sim[4,10]$ & Pallet \\
\hline$\xi_{l}^{s}$ & $\mathrm{U} \sim[0,1]$ & Percentage & $A_{q}$ & $\mathrm{U} \sim[0.01,0.4]$ & Pallet \\
\hline$U S_{q}^{s}$ & $\mathrm{U} \sim[100000,185000]$ & Rial (R) & $\phi_{s}^{g}$ & $\mathrm{U} \sim[0,1]$ & Percentage \\
\hline$\zeta_{i j m}^{s}$ & 0 or 1 & - & $\rho_{q l}$ & 0 or 1 & - \\
\hline$C T_{q l i m}$ & \multicolumn{4}{|c|}{$\mathrm{U} \sim[$ distance $(\mathrm{km}) \times 10000(R)$, distance $(\mathrm{km}) \times 100000(R)]$} & Rial (R) \\
\hline$C T R_{q i j k m}$ & \multicolumn{4}{|c|}{$\mathrm{U} \sim[$ distance $(\mathrm{km}) \times 10000(R)$, distance $(\mathrm{km}) \times 100000(R)]$} & Rial (R) \\
\hline
\end{tabular}

482

483

Table 7. The pairwise distance of the candidate cities used in the case study (KM)

\begin{tabular}{|c|c|c|c|c|c|c|c|c|c|c|c|c|c|c|c|c|}
\hline City & 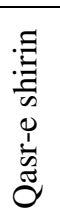 & 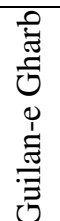 & 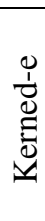 & 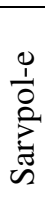 & 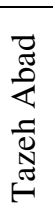 & $\sum_{0}^{5}$ & 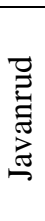 & 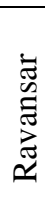 & 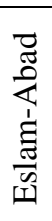 & 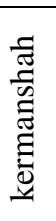 & 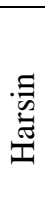 & 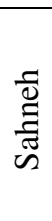 & $\begin{array}{l}\overline{0} \\
\bar{\sigma} \\
\tilde{\sigma} \\
\mathscr{n}\end{array}$ & 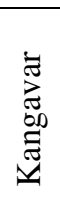 & 䓌 & 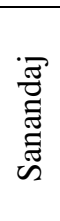 \\
\hline Qasr-e shirin & * & $*$ & * & $*$ & $*$ & * & $*$ & * & $*$ & $*$ & $*$ & $*$ & $*$ & $*$ & $*$ & $*$ \\
\hline $\begin{array}{l}\text { Guilan-e } \\
\text { Gharb }\end{array}$ & 23 & $*$ & $*$ & $*$ & $*$ & $*$ & $*$ & $*$ & $*$ & * & $*$ & $*$ & $*$ & $*$ & $*$ & $*$ \\
\hline Kerned-e & 46 & 23 & * & $*$ & $*$ & * & $*$ & * & $*$ & $*$ & $*$ & $*$ & $*$ & $*$ & $*$ & $*$ \\
\hline
\end{tabular}




\begin{tabular}{|c|c|c|c|c|c|c|c|c|c|c|c|c|c|c|c|c|}
\hline Gharb & & & & & & & & & & & & & & & & \\
\hline $\begin{array}{l}\text { Sarvpol-e } \\
\text { Zahab }\end{array}$ & 66 & 37 & 20 & $*$ & $*$ & $*$ & $*$ & $*$ & $*$ & $*$ & $*$ & $*$ & $*$ & $*$ & $*$ & $*$ \\
\hline Tazeh Abad & 62 & 43 & 20 & 20 & $*$ & $*$ & $*$ & $*$ & $*$ & $*$ & $*$ & $*$ & $*$ & $*$ & $*$ & $*$ \\
\hline Paveh & $\begin{array}{c}11 \\
6\end{array}$ & 93 & 70 & 70 & 50 & $*$ & $*$ & $*$ & $*$ & $*$ & $*$ & $*$ & $*$ & $*$ & $*$ & $*$ \\
\hline Javanrud & $\begin{array}{l}11 \\
0\end{array}$ & 90 & 65 & 65 & 45 & 10 & $*$ & $*$ & $*$ & $*$ & $*$ & $*$ & $*$ & $*$ & $*$ & $*$ \\
\hline Ravansar & $\begin{array}{c}10 \\
6\end{array}$ & 83 & 60 & 34 & 40 & 90 & 86 & $*$ & $*$ & $*$ & $*$ & $*$ & $*$ & $*$ & $*$ & $*$ \\
\hline $\begin{array}{l}\text { Eslam-Abad } \\
\text { Gharb }\end{array}$ & 82 & 63 & 40 & 43 & 20 & 70 & 65 & 20 & $*$ & $*$ & $*$ & $*$ & $*$ & $*$ & $*$ & $*$ \\
\hline kermanshah & $\begin{array}{c}13 \\
5\end{array}$ & $\begin{array}{c}11 \\
2\end{array}$ & 89 & 75 & 69 & $\begin{array}{c}11 \\
9\end{array}$ & $\begin{array}{c}11 \\
0\end{array}$ & 41 & 49 & $*$ & $*$ & $*$ & $*$ & $*$ & $*$ & $*$ \\
\hline Harsin & $\begin{array}{l}11 \\
5\end{array}$ & 92 & 69 & 72 & 49 & 99 & 96 & 39 & 29 & 20 & $*$ & $*$ & $*$ & $*$ & $*$ & $*$ \\
\hline Sahneh & $\begin{array}{c}16 \\
0\end{array}$ & $\begin{array}{c}13 \\
7\end{array}$ & $\begin{array}{c}11 \\
4\end{array}$ & $\begin{array}{c}12 \\
9\end{array}$ & 94 & $\begin{array}{c}14 \\
4\end{array}$ & $\begin{array}{c}14 \\
2\end{array}$ & 66 & 74 & 25 & 45 & $*$ & $*$ & $*$ & $*$ & $*$ \\
\hline Sonqor & $\begin{array}{c}20 \\
9\end{array}$ & $\begin{array}{c}18 \\
6\end{array}$ & $\begin{array}{c}16 \\
3\end{array}$ & $\begin{array}{c}13 \\
5\end{array}$ & $\begin{array}{c}16 \\
3\end{array}$ & $\begin{array}{c}19 \\
3\end{array}$ & $\begin{array}{l}19 \\
0\end{array}$ & $\begin{array}{c}11 \\
5\end{array}$ & $\begin{array}{c}12 \\
3\end{array}$ & 74 & 14 & 49 & $*$ & $*$ & $*$ & $*$ \\
\hline Kangavar & $\begin{array}{c}21 \\
0\end{array}$ & $\begin{array}{c}18 \\
7\end{array}$ & $\begin{array}{c}16 \\
4\end{array}$ & $\begin{array}{c}15 \\
0\end{array}$ & $\begin{array}{c}14 \\
4\end{array}$ & $\begin{array}{l}19 \\
4\end{array}$ & $\begin{array}{c}19 \\
1\end{array}$ & $\begin{array}{c}11 \\
6\end{array}$ & $\begin{array}{c}12 \\
4\end{array}$ & 75 & 95 & 50 & 5 & $*$ & $*$ & $*$ \\
\hline Ilam & $\begin{array}{c}27 \\
1\end{array}$ & $\begin{array}{c}24 \\
8\end{array}$ & $\begin{array}{c}22 \\
5\end{array}$ & $\begin{array}{c}21 \\
1\end{array}$ & $\begin{array}{l}19 \\
0\end{array}$ & $\begin{array}{c}25 \\
5\end{array}$ & $\begin{array}{c}25 \\
0\end{array}$ & $\begin{array}{l}17 \\
7\end{array}$ & $\begin{array}{c}18 \\
4\end{array}$ & $\begin{array}{c}13 \\
2\end{array}$ & $\begin{array}{c}15 \\
6\end{array}$ & $\begin{array}{c}10 \\
7\end{array}$ & 62 & 57 & $*$ & $*$ \\
\hline Sanandaj & $\begin{array}{c}29 \\
6\end{array}$ & $\begin{array}{c}26 \\
9\end{array}$ & $\begin{array}{c}24 \\
6\end{array}$ & $\begin{array}{c}25 \\
3\end{array}$ & $\begin{array}{c}23 \\
0\end{array}$ & $\begin{array}{c}28 \\
0\end{array}$ & $\begin{array}{l}27 \\
4\end{array}$ & $\begin{array}{c}20 \\
2\end{array}$ & $\begin{array}{c}21 \\
0\end{array}$ & $\begin{array}{c}15 \\
7\end{array}$ & $\begin{array}{c}18 \\
1\end{array}$ & $\begin{array}{c}13 \\
2\end{array}$ & 87 & 82 & 25 & $*$ \\
\hline
\end{tabular}

484

485 


\section{Computational results}

Here, the computational results of solving proposed model is reported. To this end, at first the resilience parameters used for second objective should be obtained using BWM. Then, other parameters of the model must be generated. Besides, to gain better execution, the method of Taguchi is employed for tuning the metaheuristics' parameters. Finally, the results and discussion are provided.

The proposed mathematical model is coded in the GAMS 2017 and MATLAB ${ }^{\mathrm{TM}} 2013$ software. All of the program runs are performed on a PC with Intel(R) Core (TM) i5-5200U CPU @2.20 GHz under Windows 10. Besides, each test problem was calculated utilizing the advanced algorithms based on the most favorable parameters according to Taguchi experiments.

\subsection{Finding the resilient parameters}

In the proposed bi-objective mathematical model, two resilient parameters include $\alpha_{\mathrm{i}}$ and $\theta_{\mathrm{j}}$ are existed which to find them values the BWM method is applied. To perform this MCDM method, two components include the alternatives and criteria are needed. Here, for $\alpha_{\mathrm{i}}$, the i CWs are the alternatives and for $\theta_{\mathrm{j}}$, the $\mathrm{j}$ LDCs are the alternatives. Also, the criteria of Table 2 are utilized. For instance, in first test problem, $i=2$ and $j=3$, so the $\alpha_{1}, \alpha_{2}, \theta_{1}, \theta_{2}$, and $\theta_{3}$ should be obtain.

Based on experts' and DMs opinions, Flexible facilities (C2) and Distributed power empowered to take necessary action (C4) as the best criterion and worst criterion are selected, respectively. So, the Best-to-Others vector, and Others-to-Worst vector are provided in Table 8-9, respectively. Then, solving the presented problem in equation (20), the global weights of indicators result. The problem (20) is coded in Lingo software and finally values of (0.06, $0.03,0.31,0.18,0.11,0.15,0.12,0.04,1.228)$ are obtained for $\left(\omega_{1}, \omega_{2}, \omega_{3}, \omega_{4}, \omega_{5}, \omega_{6}, \omega_{7}, \omega_{8}, \xi\right)$, respectively.

Table 8. Best-to-Others vector.

\begin{tabular}{|l|l|l|l|l|l|l|l|l|}
\hline Criteria & $\mathrm{C}_{1}$ & $\mathrm{C}_{2}$ & $\mathrm{C}_{3}$ & $\mathrm{C}_{4}$ & $\mathrm{C}_{5}$ & $\mathrm{C}_{6}$ & $\mathrm{C}_{7}$ & $\mathrm{C}_{8}$ \\
\hline Best criterion $\mathbf{C}_{2}$ & 5 & 1 & 2 & 9 & 4 & 2 & 3 & 8 \\
\hline
\end{tabular}

Table 9. Others-to-Worst vector.

\begin{tabular}{|l|l|}
\hline Criteria & Worst criterion $\mathbf{C}_{\mathbf{4}}$ \\
\hline $\mathrm{C}_{1}$ & 3 \\
\hline $\mathrm{C}_{2}$ & 9 \\
\hline $\mathrm{C}_{3}$ & 7 \\
\hline $\mathrm{C}_{4}$ & 1 \\
\hline $\mathrm{C}_{5}$ & 4 \\
\hline $\mathrm{C}_{6}$ & 6 \\
\hline $\mathrm{C}_{7}$ & 4 \\
\hline $\mathrm{C}_{8}$ & 2 \\
\hline
\end{tabular}


511 Finally, to calculate the score of CWs and LDCs, at first, the experts give the score to the alternatives based on each indicator (Table 120-11). Then, the final scores and normalized manner of alternatives are resulted in Table 12 using

513 the formulas (22) and (23). Similarly, for other test problems the values of $\alpha_{\mathrm{i}}$ and $\theta_{\mathrm{j}}$ can be found.

514

Table 10. The scoring of the CWs based on the criteria.

\begin{tabular}{|l|l|l|l|l|l|l|l|l|}
\hline \multirow{2}{*}{ Alternatives } & \multicolumn{7}{|c|}{ Criteria } \\
\cline { 2 - 10 } & $\mathrm{C}_{1}$ & $\mathrm{C}_{2}$ & $\mathrm{C}_{3}$ & $\mathrm{C}_{4}$ & $\mathrm{C}_{5}$ & $\mathrm{C}_{6}$ & $\mathrm{C}_{7}$ & $\mathrm{C}_{8}$ \\
\hline$\alpha_{1}$ & 4 & 6 & 3 & 5 & 3 & 4 & 2 & 2 \\
\hline$\alpha_{2}$ & 5 & 6 & 5 & 4 & 4 & 2 & 2 & 3 \\
\hline
\end{tabular}

Table 11. The scoring of the LDCs based on the criteria.

\begin{tabular}{|l|l|l|l|l|l|l|l|l|}
\hline \multirow{2}{*}{ Alternatives } & \multicolumn{7}{|c|}{ Criteria } \\
\cline { 2 - 10 } & $\mathrm{C}_{1}$ & $\mathrm{C}_{2}$ & $\mathrm{C}_{3}$ & $\mathrm{C}_{4}$ & $\mathrm{C}_{5}$ & $\mathrm{C}_{6}$ & $\mathrm{C}_{7}$ & $\mathrm{C}_{8}$ \\
\hline$\theta_{1}$ & 6 & 4 & 6 & 6 & 3 & 3 & 2 & 2 \\
\hline$\theta_{2}$ & 5 & 7 & 9 & 6 & 2 & 4 & 3 & 4 \\
\hline$\theta_{3}$ & 2 & 7 & 5 & 6 & 5 & 5 & 4 & 2 \\
\hline
\end{tabular}

Table 12. The attained score of alternatives based on the criteria

\begin{tabular}{|l|l|l|}
\hline Alternatives & $\mathrm{S}_{\mathrm{i}}$ & Normalized Scor \\
\hline$\alpha_{1}$ & 4.049 & $\mathbf{0 . 4 8 6}$ \\
\hline$\alpha_{2}$ & 4.285 & $\mathbf{0 . 5 1 4}$ \\
\hline$\theta_{1}$ & 3.943 & $\mathbf{0 . 2 0 7}$ \\
\hline$\theta_{2}$ & 5.601 & $\mathbf{0 . 2 9 3}$ \\
\hline$\theta_{3}$ & 9.544 & $\mathbf{0 . 5 0 0}$ \\
\hline
\end{tabular}

521 As discussed earlier, the LP-metric method was used in this study. The input parameters of the LP-metric method

522 for 10 test problem are shown in Table 13. According to opinion experts, the weight for the first, second objective 523 function is, respectively $0.6,0.4$.

Table 13. The input parameters of the LP-metric method

\begin{tabular}{|c|c|c|c|}
\hline \multirow[t]{2}{*}{ \# of problem } & & \multirow[t]{2}{*}{$f_{\text {min }}$} & \multirow[t]{2}{*}{$\mathrm{f}_{\max }$} \\
\hline & $\begin{array}{l}\text { objective } \\
\text { function }\end{array}$ & & \\
\hline 1 & & 11877527.09 & 3322312.07 \\
\hline 2 & & 10438337.11 & 7287586.14 \\
\hline 3 & & 9544569.07 & 10581393.00 \\
\hline 4 & & 3822361.23 & 1726815.07 \\
\hline
\end{tabular}




\begin{tabular}{|c|c|c|c|}
\hline 5 & $\mathrm{Z}_{1}$ & 3616425.56 & 1689415.72 \\
\hline 6 & & 3581580.87 & 2792851.63 \\
\hline 7 & & 10694586.95 & 6815366.09 \\
\hline 8 & & 3121933.12 & 6041184.15 \\
\hline 9 & & 8715152.01 & 2427395.82 \\
\hline 10 & & 10130420.07 & 7424848.33 \\
\hline 1 & & 236 & 1154 \\
\hline 2 & & 350 & 927 \\
\hline 3 & & 265 & 864 \\
\hline 4 & & 228 & 1327 \\
\hline 5 & $\mathrm{Z}_{2}$ & 260 & 1345 \\
\hline 6 & & 358 & 1156 \\
\hline 7 & & 339 & 1456 \\
\hline 8 & & 207 & 1289 \\
\hline 9 & & 232 & 1450 \\
\hline 10 & & 262 & 1605 \\
\hline
\end{tabular}

526 The outcomes of the suggested model solution are exhibited in Table 14. As you can see, the optimal LP-Metric 527 model is tested in three types (MINLP, MILP, and Heuristic) and two modes (Deterministic, Robust) and the 528 optimal GAP is shown.

529 Table 14. Comparison among MINLP, MILP, heuristic and robust LP-Metric model solutions for problems 530 possessing are solved under uncertain characteristics. 


\begin{tabular}{|c|c|c|c|c|c|c|c|c|c|c|c|c|c|c|c|c|c|c|}
\hline \multirow[b]{2}{*}{ 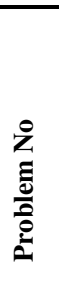 } & \multicolumn{6}{|c|}{ MINLP } & \multicolumn{6}{|c|}{ MILP } & \multicolumn{6}{|c|}{ Heuristics } \\
\hline & 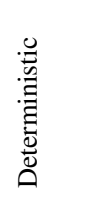 & $\stackrel{\Xi}{\Xi}$ & 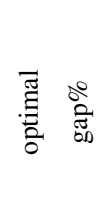 & $\begin{array}{l}\vec{a} \\
\overrightarrow{0} \\
\stackrel{0}{\Omega}\end{array}$ & $\stackrel{\Xi}{\Xi}$ & 䒱总 & 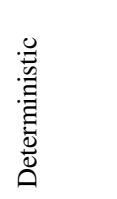 & $\stackrel{\Xi}{\Xi}$ & 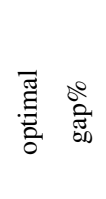 & $\begin{array}{l}\vec{a} \\
\overrightarrow{0} \\
\stackrel{2}{q}\end{array}$ & $\stackrel{\Xi}{\Xi}$ & 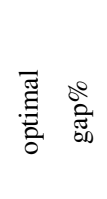 & 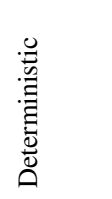 & $\stackrel{\Xi}{\Xi}$ & 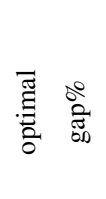 & $\begin{array}{l}\overrightarrow{0} \\
\overrightarrow{0} \\
\stackrel{0}{\alpha}\end{array}$ & $\stackrel{\Xi}{\Xi}$ & 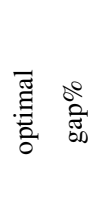 \\
\hline 1 & 0.233 & 0:04:00 & 2.8 & 0.203 & 0:04:56 & 1.56 & 0.161 & 0:02:00 & 2.02 & 0.149 & 0:02:00 & 1.85 & 0.147 & 0:01:03 & 2.5 & 0.133 & $0: 02: 23$ & 1.05 \\
\hline 2 & 0.188 & 0:04:19 & 0.51 & 0.168 & 0:05:00 & 1.04 & 0.111 & 0:01:00 & 0.036 & 0.101 & 0:01:15 & 0.5 & 0.091 & $0: 01: 10$ & 0.00 & 0.080 & 0:02:46 & 1.2 \\
\hline 3 & 0.219 & 0:04:55 & 0.00 & 0.209 & 0:05:34 & 0.94 & 0.189 & 0:02:00 & 1.68 & 0.171 & 0:02:38 & 0.008 & 0.168 & 0:01:09 & 1.05 & 0.153 & 0:03:19 & 0.00 \\
\hline 4 & 0.298 & 0:06:56 & 0.82 & 0.304 & 0:07:41 & 0.00 & 0.241 & 0:04:56 & 0.39 & 0.228 & 0:05:06 & 1.36 & 0.225 & $0: 02: 11$ & 0.005 & 0.220 & $0: 05: 17$ & 0.00 \\
\hline 5 & 0.320 & $0: 3: 20$ & 1.18 & 0.289 & 0:10:00 & 0.76 & 0.236 & 0:10:00 & 3.35 & 0.213 & 0:10:58 & 2.59 & 0.205 & 0:02:01 & 0.069 & 0.198 & 0:07:39 & 1.006 \\
\hline 6 & 0.210 & $00: 34: 44$ & 2.71 & 0.187 & 00:38:00 & 0.83 & 0.144 & $00: 35: 24$ & 0.32 & 0.131 & $00: 36: 51$ & 3.61 & 0.123 & $0: 02: 11$ & 2.03 & 0.118 & 0:08:42 & 2.13 \\
\hline 7 & 0.168 & $00: 44: 15$ & 0.19 & 0.123 & 00:55:47 & 3.22 & 0.098 & $00: 54: 41$ & 3.12 & 0.076 & $00: 54: 41$ & 0.41 & 0.066 & 0:03:04 & 0.04 & 0.057 & 0:11:04 & 0.13 \\
\hline 8 & 0.189 & 00:57:02 & 0.00 & 0.146 & $00: 43: 35$ & 5.05 & 0.118 & $00: 37: 41$ & 0.795 & 0.098 & $00: 37: 41$ & 3.66 & 0.092 & 0:03:01 & 2.14 & 0.087 & $0: 13: 49$ & 0.065 \\
\hline 9 & 0.157 & $00: 17: 32$ & 0.00 & 0.129 & 00:28:02 & 4.03 & 0.103 & $00: 10: 32$ & 0.12 & 0.073 & 00:11:00 & 0.5 & 0.065 & 0:04:54 & 1.04 & 0.049 & $0: 16: 50$ & 0.0085 \\
\hline 10 & 0.288 & 00:41:05 & 1.15 & 0.210 & 00:33:00 & 2.33 & 0.147 & 00:33:00 & 0.1 & 0.139 & $00: 33: 39$ & 0.24 & 0.135 & 0:04:56 & 0.06 & 0.129 & $0: 17: 36$ & 0.3 \\
\hline
\end{tabular}

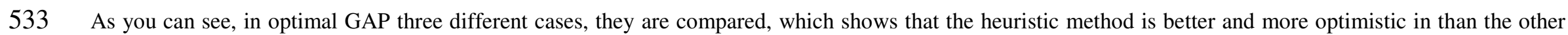
534 two.

535 As you can see in Table 14, the model is on the basis of four kinds of problem-solving, and the outcomes are as below:

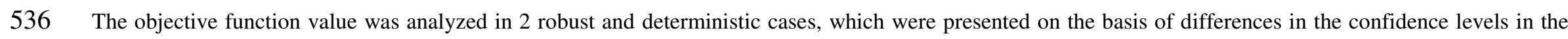

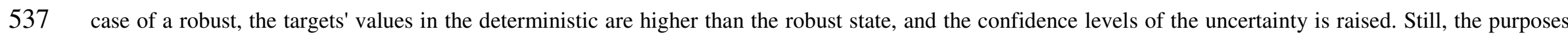

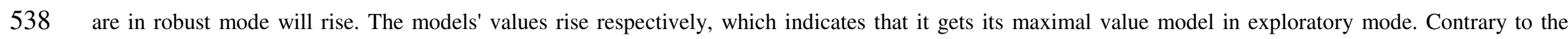

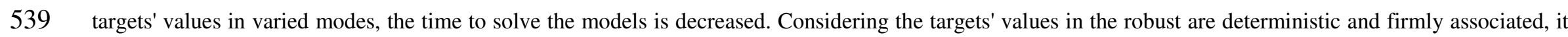

540 can be argued that the model is steady and integrated. 
The objective function's

values

Model's CPU Time values
$\operatorname{MINLP}_{\text {Deterministic }} \leq$ MILP $_{\text {Deterministic }} \leq$ Heuristics $_{\text {Deterministic }}$

$$
\begin{gathered}
\operatorname{MINLP}_{\text {Robust }} \leq \operatorname{MILP}_{\text {Robust }} \leq \text { Heuristics }_{\text {Robust }} \\
\operatorname{MINLP}_{\text {Deterministic }} \geq \operatorname{MILP}_{\text {Deterministic }} \geq \text { Heuristics }_{\text {Deterministic }} \\
\text { MINLP }_{\text {Robust }} \geq \text { MILP }_{\text {Robust }} \geq \text { Heuristics } \\
\text { Robust }
\end{gathered}
$$

In this study to set the parameter for the proposed algorithm, since the objective functions are considered as

544 variables. The initial population size, crossover probabilities, mutation probabilities according to their definition in 545 section 4.4 we use the slope linear regression method through the data points proposed by Shah et al. (2018). We use 546 the method to discover the optimal levels of the problem. The highest slope linear regression method should be 547 selected for the best level of each factor. Thus, using main excellence of this response points it can be found that, $548\{$ Max-iteration $=200, \mathrm{Pc}=0.7, \mathrm{~N}-\mathrm{pop}=150, \mathrm{Pm}=0.05\}$ are the chosen values for parameters of LP-GA. Since, the 549 model has multiple objectives, so ideal response based on the multi-objective measure metrics is provided for the 550 response of LP-metric technique in this examination.

551 Given the equation (41) relative error (PRE) for small samples of the problem is calculated as follows:

$$
\mathrm{PRE}=\frac{\mathrm{ALG}_{\mathrm{sol}}-\mathrm{OPT}_{\mathrm{sol}}}{\mathrm{OPT}_{\mathrm{sol}}} \times 100
$$

where, $\mathrm{OPT}_{\mathrm{sol}}$ and $\mathrm{ALG}_{\mathrm{sol}}$ are the optimum value acquired by the GAMS software and the objective value acquired 553 by each suggested GA, in turn.

554 Plus, utilizing formula (42), we are able to normalize the resulting data. In this formula RPD defined Related 555 Percentage Deviation.

$$
\mathrm{RPD}=\mid \text { Every Experiment Sol }- \text { Best Sol }|* 100 /| \text { Best Sol } \mid
$$

\subsection{Results and discussion}

558 Here, the reaction of the developed metaheuristic algorithms is assessed by the standard metrics assumed in Section 559 6.1. To this end, after solving the proposed model using mentioned algorithms, the obtain results are provide in Table 15. These values are reported for 10 test problems introduced in Section 5. 
Table 15. Results of computational for the problem

\begin{tabular}{|c|c|c|c|c|c|c|c|}
\hline & \multicolumn{2}{|c|}{ GAMS } & \multicolumn{5}{|c|}{ LP-GA } \\
\hline & Optimal & CPU Time & Best & Avg. & RPD & PRE & CPU Time \\
\hline 1 & 0.133 & $0: 02: 23$ & 0.136 & 0.145 & 0.00 & 1.26 & $0: 30: 21$ \\
\hline 2 & 0.080 & $0: 02: 46$ & 0.085 & 0.115 & 1.30 & 0.38 & $0: 35: 11$ \\
\hline 3 & 0.153 & 0:03:19 & 0.168 & 0.189 & 1.10 & 1.26 & $0: 38: 25$ \\
\hline 4 & 0.220 & $0: 05: 17$ & 0.243 & 0.268 & 1.30 & 3.11 & $0: 42: 28$ \\
\hline 5 & 0.198 & $0: 07: 39$ & 0.111 & 0.205 & 1.50 & 1.17 & $0: 49: 41$ \\
\hline 6 & 0.118 & $0: 08: 42$ & 0.152 & 0.175 & 1.80 & 0.26 & $0: 47: 23$ \\
\hline 7 & 0.057 & 0:11:04 & 0.097 & 0.105 & 1.60 & 2.89 & $0: 53: 18$ \\
\hline 8 & 0.087 & $0: 13: 49$ & 0.024 & 0.109 & 1.90 & 1.26 & $0: 52: 36$ \\
\hline 9 & 0.049 & $0: 16: 50$ & 0.056 & 0.085 & 2.10 & 3.27 & $0: 57: 17$ \\
\hline 10 & 0.129 & $0: 17: 36$ & 0.165 & 0.179 & 2.00 & 3.10 & 01:05:28 \\
\hline
\end{tabular}

According to Table 15 comparing the results of the proposed model solution for the Problem instances for Heuristics

- Robust Model between LP model and LP-GA it has been shown. According to it we found that the effectiveness of the proposed solution was better at solving time and response quality. Also, the LP-GA approach was more stable under uncertainty, although the LP-GA-time solution is slightly longer than the GAMS solution time so the amount of time increase is justified.

\subsection{The analysis of sensitivity}

575 In the present part, the sensitivity examination of the objective function is contrasted with several model parameters

576 to define the impact of the difference in the objective function value. For this purpose, a test problem is selected, and 577 the value of all parameters other than demand is constant, and the problem is solved in different situations.

578 This section examines the changes made during the total cost (first objective function) and the weighted resilience 579 level of each facility, CW/LDC (second objective function), regarding the change in the demand. For this purpose, a 580 case study of the problem is considered, and all parameters other than fixed demand are considered, then the 581 problem is solved with different demand values to determine its impact upon the problem's objective functions. The 582 result demonstrates the objective functions' sensitivity analysis in relation to the amount of demand in Fig. 11 and 58312. 


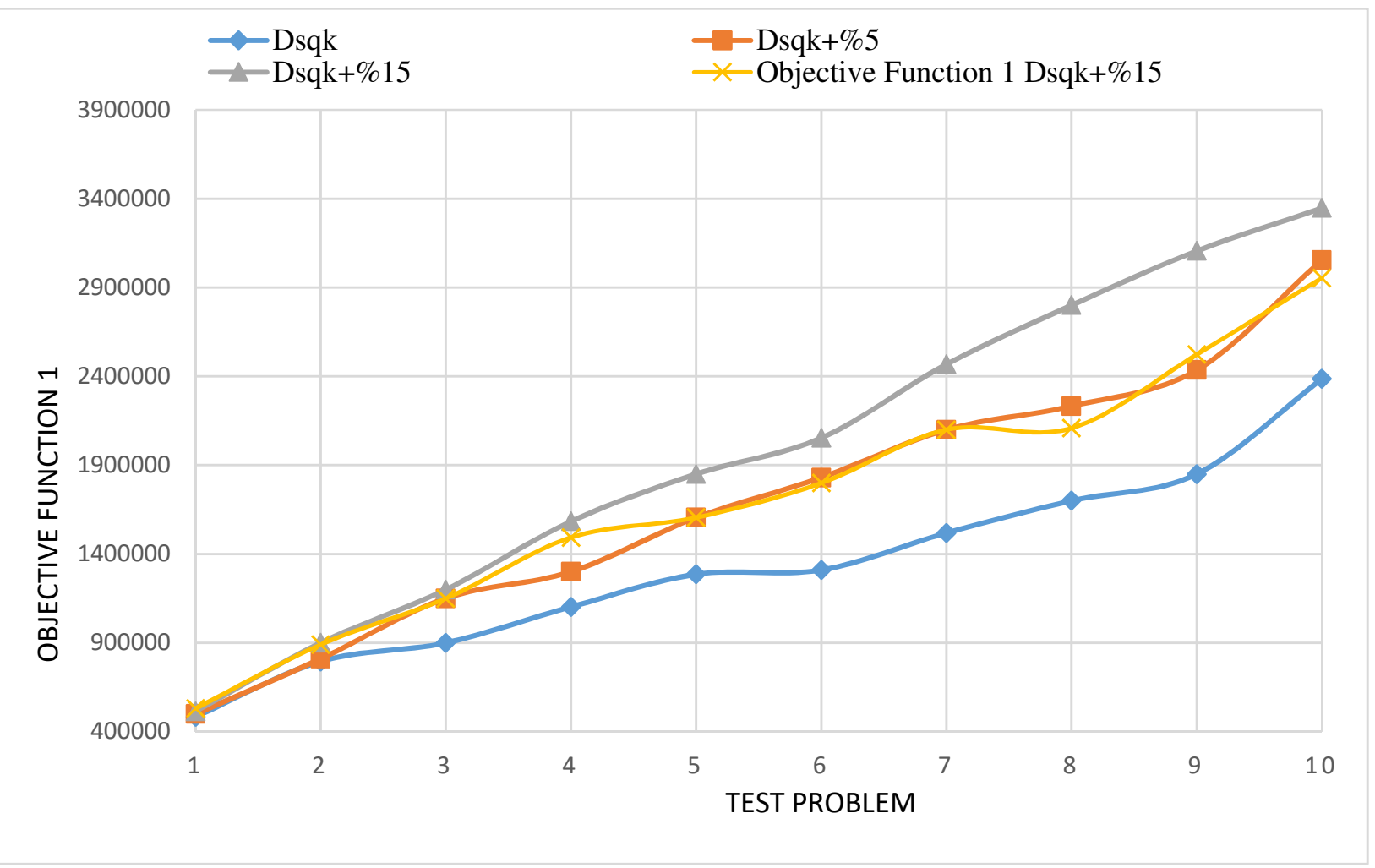

586

587

588

589

590

591

592

593 As shown in Fig. 11 and 12, the objective functions represent a direct relationship with the parameters change. To 594

Fig. 11. To analyze the sensitivity of demand for the first objective function

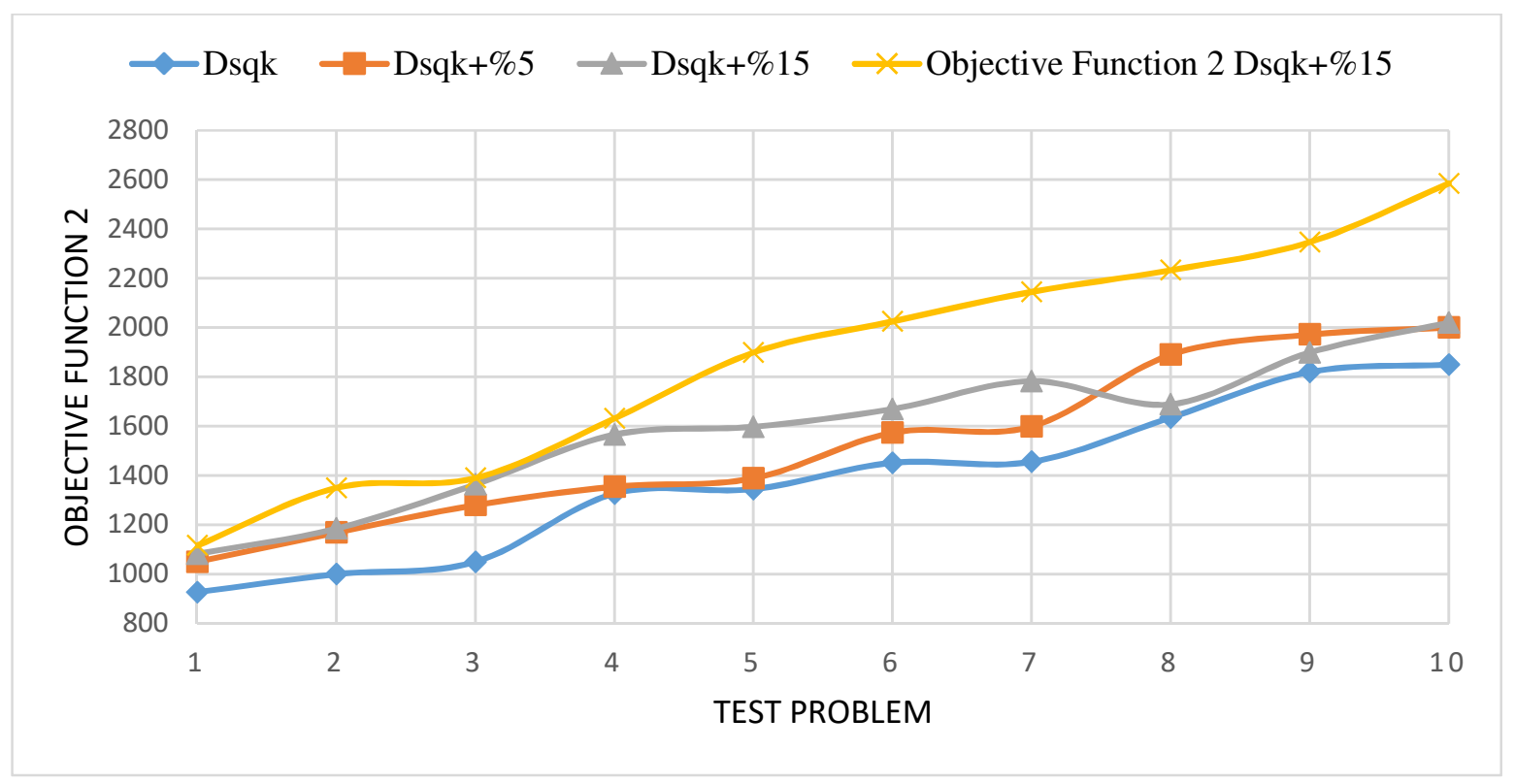

Fig. 12. To analyze the sensitivity of demand for the second objective function

put it another way, they rise by the development of the different amount of demand. Nevertheless, those fluctuations 

intervals.

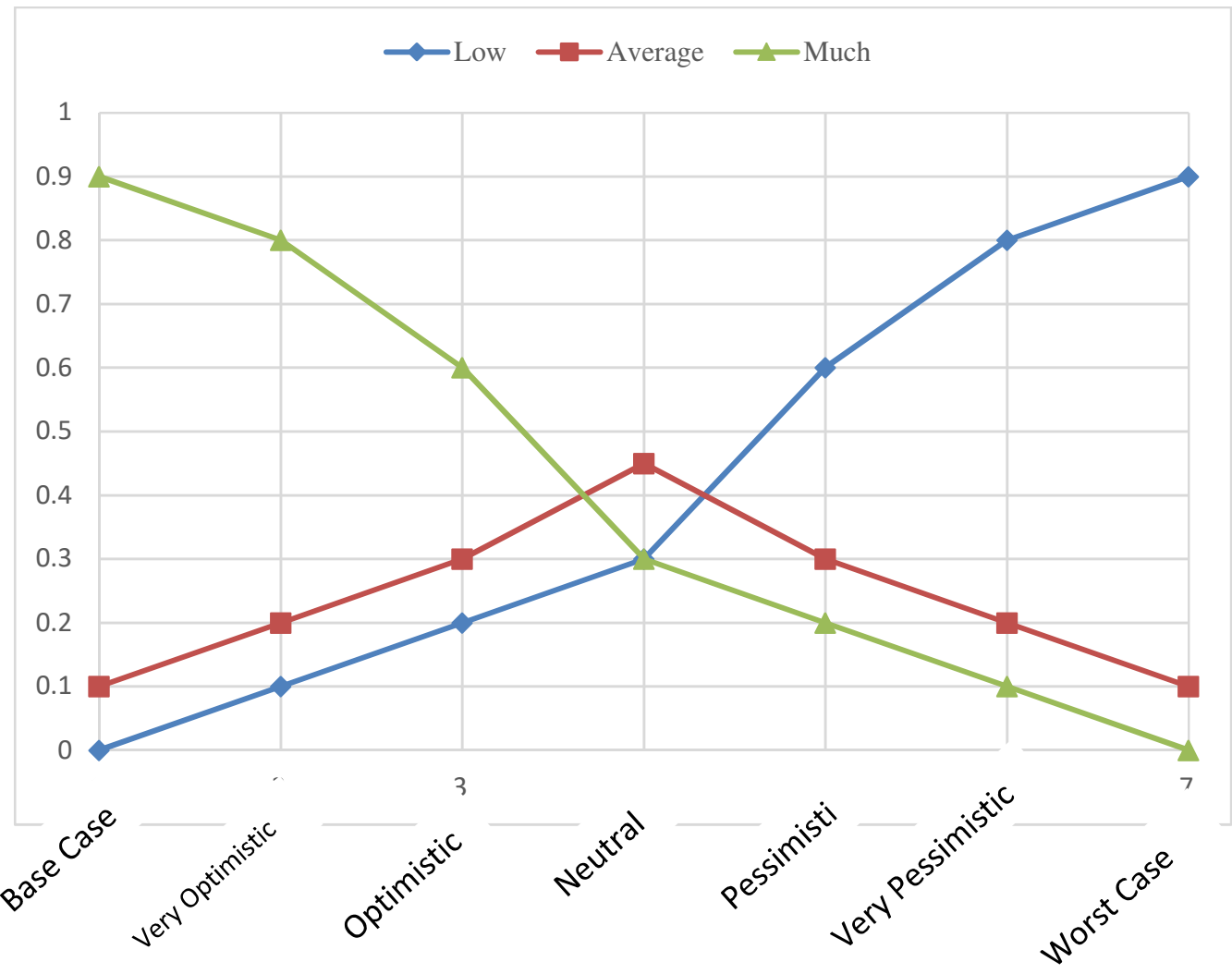

600

601

602

Fig. 13. The probability of each scenario for different modes

603

604 As given in Fig. 13, it illustrates the different changes and probabilities in different scenarios at the case study level. 605

606 


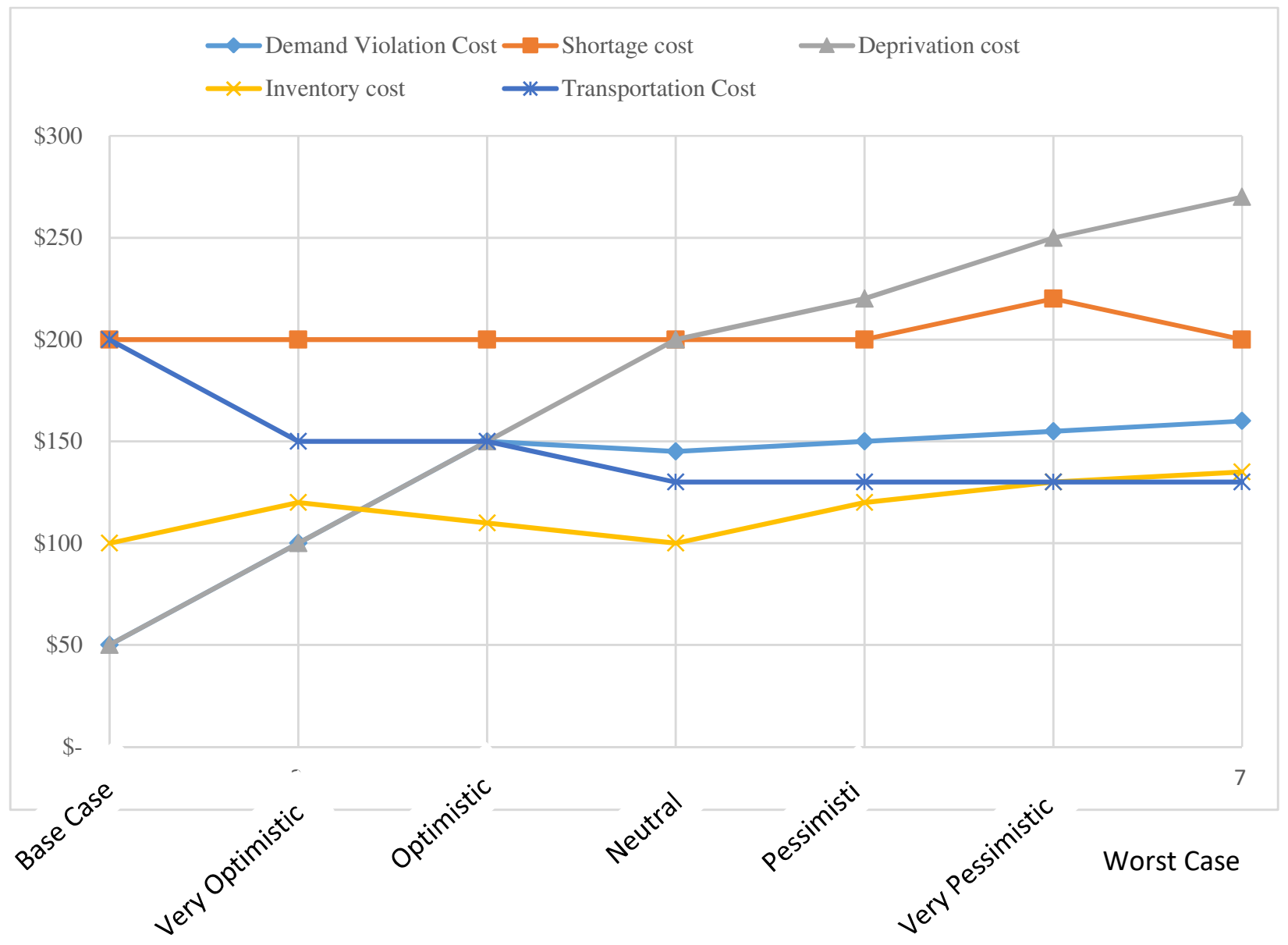

Fig. 14. The different scenarios effect on optimal supply chain cost parameters examined

616 The scenario possibilities effect on the optimal components of logistic relief costs is presented in Fig. 14. In the case

617 described earlier, altering the conditions does not significantly affect optimal transportation costs and Short-term 618 costs.

\section{Conclusion}

The present study provides a bi-objective MINLP model to identify the locations of LDCs and CWs, at the same 622 time, and the corresponding inventoried relief commodities, and the distributed quantities to CWs from supplier, 623 from CWs to the damaged regions (LDC), and from strategic stock to LDC. To this end, this paper provides a base 624 scenario bi-objective model that seeks to reduce total cost consisting of inventory holding cost, shortage and transportation cost while maximizing the level of the weighted resilience of each facility (CW/LDC). Here, a novel robust optimization approach is employed to deal with the uncertainty level of the transport network paths, supply condition, amount of demand and deprivation costs are assumed. Also, based on historical data, several scenarios are 
defined which represent $\mathrm{S}$ disaster conditions. Also, the resilience parameters used for the second objective are obtained using BWM. Moreover, the multiple disasters (sub-sequent minor post disasters) which can increase the initial demand are considered. Furthermore, in view of the NP-Hardness of the model, the well-known metaheuristic algorithm LP-GA is employed, and their performance is compared per 10 test problems by several standard singleobjective measure metrics. The present article has revealed that with the integration of LP-GA into models, the model calculating time is decreased. Due to the nonlinearity of the model, the solution time is raised; for solving this issue, the vast range for relaxation of the created model has been employed, which decreases the computing time by roughly $27 \%$. Finally, according to the results, it was exposed that: LP-GA has better proficiency in terms of RPD, PRE; meanwhile, for CPU time, LP-GA has better performances. The achieved results prove that a statistically significant difference is observed among the performances of the metaheuristics. The results demonstrate the effectiveness of suggested model and framework and these results can be helpful for crisis managers. Finally, as management recommendations for future research and recommendations are as follows:

The lack of access to media after the disaster has prevented critical information from being released. That can be conducted through installing banners concerning the specific locations with more vulnerability informed.

642 Information on critical needs created after the disaster: Avoid unnecessary dispatch of goods to the affected areas. In 643 the earthquake disaster of Kermanshah, 2018 in Iran, one of the major problems with overloading private vehicles 644 such as clothing packs and blankets to the affected areas has been the disruption to assisting the injured. Therefore, 645 the needs of the injured should be addressed with appropriate assistance and those of the army and the Red Crescent.

$>$ The model can be formulated using a fuzzy set theory or another approach such as robust stochastic programming for formulating the model.

$>$ Utilizing the suggested model in other sectors of logistics.

Developing some hybrid meta-heuristics and heuristics to solve the model.

$>$ Applying other MCDM methods such as TOPSIS, AHP, and DEMATEL to find resilient parameters.

\section{Declarations}

- Ethics approval and consent to participate: Not Applicable.

- Consent for publication: Not Applicable.

- Availability of data and materials: Data sharing is not applicable to this article as no datasets were generated or analyzed during the current study.

- Competing interests: The authors declare no competing interests. review; AF, BFM, MHB, and FMS: data discussion. All the authors approved the final version of the manuscript. 
665 Afshar, Mohasel, A. (2011). A mathematical framework for optimizing disaster relief logistics.

666 Akgün, İ., Gümüşbuğa, F., \& Tansel., B. (2015). Risk based facility location by using fault tree analysis in disaster 667 management. Omega. 52, 168-179

668 Barzinpour, F., \& Esmaeili., V. (2014). A multi-objective relief chain location distribution model for urban disaster 669 management. Int. J. Adv. Manuf. Technol. 70, 1291-1302

670 Behl, A., \& Dutta, P. (2018). Humanitarian supply chain management: a thematic literature review and future directions 671 of research. Annals of Operations Research, 1-44.

672 Cao, C., Li, C., Yang, Q., Liu, Y., \& Qu, T. (2018). A novel multi-objective programming model of relief distribution 673 for sustainable disaster supply chain in large-scale natural disasters. J. Clean. Prod. 174, 1422-1435 674 https://doi.org/https://doi.org/10.1016/j.jclepro.2017.11.037

675 Caunhye, A.M., Nie, X., \& Pokharel, S. (2012). Optimization models in emergency logistics: A literature review. 676 Socioecon. Plann. Sci. 46, 4-13

677 Charles, A., Lauras, M., Van Wassenhove, L. N., \& Dupont, L. (2016). Designing an efficient humanitarian supply 678 network. Journal of Operations Management, 47, 58-70.

679 Diabat, A., \& Deskoores, R. (2016). A hybrid genetic algorithm based heuristic for an integrated supply chain problem. 680 J Manuf Syst 38:172-180

681 Elluru, S., Gupta, H., Kaur, H., \& Singh, S. P. (2017). Proactive and reactive models for disaster resilient supply chain. 682 Annals of Operations Research. https://doi.org/10.1007/s10479-017-2681-2.

683 Fahimnia, B., Jabbarzadeh, A., Ghavamifar, A., \& Bell, M. (2017). Supply chain design for efficient and effective blood 684 supply in disasters. Int. J. Prod. Econ. 183, 700-709 https://doi.org/https://doi.org/10.1016/j.ijpe.2015.11.007

685 Fathollahi-Fard, A. M., Hajiaghaei-Keshteli, M. \& Tavakkoli-Moghaddam, R., (2020). Red deer algorithm (RDA): a 686 new nature-inspired meta-heuristic, Soft Computing, 10.1007/s00500-020-04812-z.

687 Galindo, G., Batta, R. (2013). Review of recent developments in OR/MS research in disaster operations management. 688 Eur. J. Oper. Res. 230, 201-211 https://doi.org/10.1016/j.ejor.2013.01.039.

689 Ghasemi, P., Khalili-Damghani, K., Hafezalkotob, A., \& Raissi, S. (2019). Uncertain multi-objective multi-commodity 690 multi-period multi-vehicle location-allocation model for earthquake evacuation planning. Appl. Math. Comput. 350, 691 105-132 https://doi.org/https://doi.org/10.1016/j.amc.2018.12.061.

692 Gen, M., Altiparmak, F., \& Lin, L. (2006). A genetic algorithm for two-stage transportation problem using priority693 based encoding. OR Spectr. 28, 337-354 https://doi.org/10.1007/s00291-005-0029-9.

694 Ghatreh Samani, M.R., Torabi, S.A., \& Hosseini-Motlagh, S.M. (2018). Integrated blood supply chain planning for 695 disaster relief. Int. J. Disaster Risk Reduct. 27, 168-188 https://doi.org/https://doi.org/10.1016/j.ijdrr.2017.10.005. 
696 Gholizadeh, H., Tajdin, A., \& Javadian, N. (2020). A closed-loop supply chain robust optimization for disposable 697 appliances. Neural computing and applications, 32(8), 3967-3985. https://doi.org/10.1007/s00521-018-3847-9.

698 Görmez, N., Köksalan, M., \& Salman, F. (2011). Locating disaster response facilities in Istanbul. J. Oper. Res. Soc. $69962,1239-1252$.

$700 \mathrm{Hu}, \mathrm{F} .$, Yang, S., \& Xu, W. (2014). A non-dominated sorting genetic algorithm for the location and districting planning 701 of earthquake shelters. Int. J. Geogr. Inf. Sci. 28, 1482-1501.

702 Jabbarzadeh, A., Fahimnia, B., \& Seuring, S. (2014). Dynamic supply chain network design for the supply of blood in 703 disasters: A robust model with real world application. Transp. Res. Part E Logist. Transp. Rev. 70, 225-244. 704 Kannan, G., Sasikumar, P., \& Devika, K. (2010). A genetic algorithm approach for solving a closed loop supply 705 chain model: a case of battery recycling. Appl Math Model 34(3):655-670.

706 Kaur, H., \& Singh, S. P. (2016). Sustainable procurement and logistics for disaster resilient supply chain. Annals of 707 Operations Research. https://doi.org/10.1007/s10479-016-2374-2.

708 Kedchaikulrat, L., \& Lohatepanont, M. (2015). Multi-Objective Location Selection Model for Thai Red Cross's Relief 709 Warehouses. Proc. East. Asia Soc. Transp. Stud. 10, 1-21

710 Khayal, D., Pradhananga, R., Pokharel, S., \& Mutlu, F. (2015). A model for planning locations of temporary 711 distribution facilities for emergency response. Socioecon. Plann. Sci. 52, 22-30

712 Kilci, F., Kara, B.Y., \& Bozkaya, B. (2015). Locating temporary shelter areas after an earthquake: A case for Turkey. 713 Eur. J. Oper. Res. 243, 323-332

714 Kunz, N., \& Gold, S. (2017). Sustainable humanitarian supply chain management—exploring new theory. International 715 Journal of Logistics Research and Applications, 20(2), 85-104.

716 Maharjan, R., \& Hanaoka, S. (2017). Warehouse location determination for humanitarian relief distribution in Nepal. 717 Transp. Res. Procedia. 25, 1151-1163 https://doi.org/https://doi.org/10.1016/j.trpro.2017.05.128.

718 Manopiniwes, W., \& Irohara, T. (2016). Stochastic optimisation model for integrated decisions on relief supply chains: 719 preparedness for disaster response. Int. J. Prod. Res. 1-18

720 Marcelin, J.M., Horner, M.W., Ozguven, E.E., \& Kocatepe, A. (2016). How does accessibility to post-disaster relief 721 compare between the aging and the general population? A spatial network optimization analysis of hurricane relief 722 facility locations. Int. J. Disaster Risk Reduct. 15, 61-72

723 Moeini, M., Jemai, Z., \& Sahin, E. (2015). Location and relocation problems in the context of the emergency medical 724 service systems: a case study. Cent. Eur. J. Oper. Res. 23, 1-18.

725 Mulvey, J. M., Vanderbei, R. J., \& Zenios, S. A. (1995). Robust optimization of large-scale systems. Operations 726 research, 43(2), 264-281. 
727 Nikkhoo, F., Bozorgi-Amiri, A., \& Heydari, J. (2018). Coordination of relief items procurement in humanitarian logistic 728 based on quantity flexibility contract. Int. J. Disaster Risk Reduct. 31, 331-340 729 https://doi.org/https://doi.org/10.1016/j.ijdrr.2018.05.024.

730 Nezhadroshan, A. M., Fathollahi-Fard, A. M., \& Hajiaghaei-Keshteli, M., (2020). A scenario-based possibilistic731 stochastic programming approach to address the resilient humanitarian logistics considering travel time and 732 resilience levels of facilities. International Journal of Systems Science: Operations \& Logistics, 1-27, 733 https://doi.org/10.1080/23302674.2020.1769766.

734 Pettit, T.J., Croxton, K.L., \& Fiksel, J. (2013). Ensuring Supply Chain Resilience: Development and Implementation of 735 an Assessment Tool. J. Bus. Logist. 34, 46-76 https://doi.org/10.1111/jbl.12009

736 Pettit, T.J., Fiksel, J., \& Croxton, K.L. (2010). Ensuring supply chain resilience: development of a conceptual 737 framework. J. Bus. Logist. 31, 1-21 https://doi.org/10.1002/j.2158-1592.2010.tb00125.x

738 Prüfer, H. (1918). Neuer Beweis eines Satzes uber Permutationen. Arch. der Math. und Phys. 27, 142-144.

739 Ransikarbum, K., \& Mason, S. J. (2016). Multiple-objective analysis of integrated relief supplies and network 740 restoration in humanitarian logistics operations. International Journal of Production Research, 54(1), 49-68.

741 Rezaei, J., Wang, J., \& Tavasszy, L. (2015). Linking supplier development to supplier segmentation using Best Worst 742 Method. Expert Syst. Appl. 42, 9152-9164 https://doi.org/10.1016/j.eswa.2015.07.073

743 Rezaei, J. (2015). Best-worst multi-criteria decision-making method. Omega. 53, 49-57 744 https://doi.org/10.1016/j.omega.2014.11.009

745 Safaei, A.S., Farsad, S., \& Paydar, M.M. (2018). Robust bi-level optimization of relief logistics operations. Appl. 746 Math. Model. 56, 359-380 https://doi.org/10.1016/j.apm.2017.12.003.

747 Safaei, A.S., Farsad, S., \& Paydar, M.M. (2018). Emergency logistics planning under supply risk and demand 748 uncertainty. Oper. Res. 1-24 https://doi.org/10.1007/s12351-018-0376-3

749 Sahebjamnia, N., Torabi, S.A., \& Mansouri, S.A. (2016). A hybrid decision support system for managing humanitarian 750 relief chains. Decis. Support Syst. https://doi.org/10.1016/j.dss.2016.11.006.

751 Salman, F.S., \& Yücel, E. (2015). Emergency facility location under random network damage: Insights from the 752 Istanbul case. Comput. Oper. Res. 62, 266-281.

753 Sarma, D., Das, A., Bera, U.K., \& Hezam, I.M. (2019). Redistribution for cost minimization in disaster management 754 under uncertainty with trapezoidal neutrosophic number. Comput. Ind. 109, 226-238 755 https://doi.org/https://doi.org/10.1016/j.compind.2019.04.004. 
756 Shah, N. A., Animasaun, I. L., Ibraheem, R. O., Babatunde, H. A., Sandeep, N., \& Pop, I. (2018). Scrutinization of the 757 effects of Grashof number on the flow of different fluids driven by convection over various surfaces. Journal of 758 Molecular liquids, 249, 980-990. https://doi.org/10.1016/j.molliq.2017.11.042.

759 Shin, Y., Kim, S., \& Moon, I. (2019). Integrated optimal scheduling of repair crew and relief vehicle after disaster. 760 Comput. Oper. Res. 105, 237-247 https://doi.org/https://doi.org/10.1016/j.cor.2019.01.015.

761 Tang, C.S. (2006). Robust strategies for mitigating supply chain disruptions. Int. J. Logist. Res. Appl. 9, 33-45 762 https://doi.org/10.1080/13675560500405584.

763 Tavana, M., Abtahi, A.-R., Caprio, D. Di, Hashemi, R., \& Yousefi-Zenouz, R. (2018). An integrated location764 inventory-routing humanitarian supply chain network with pre- and post-disaster management considerations. 765 Socioecon. Plann. Sci. 64, 21-37 https://doi.org/https://doi.org/10.1016/j.seps.2017.12.004.

766 Verma, A., \& Gaukler, G.M. (2015). Pre-positioning disaster response facilities at safe locations: An evaluation of 767 deterministic and stochastic modeling approaches. Comput. Oper. Res. 62, 197-209

$768 \mathrm{Yu}$, C. S., \& Li, H. L. (2000). A robust optimization model for stochastic logistic problems. International journal of 769 production economics, 64(1-3), 385-397.

770 Zokaee, S., Bozorgi-Amiri, A., \& Sadjadi, S.J. (2016). A robust optimization model for humanitarian relief chain 771 design under uncertainty. Appl. Math. Model. 40, 7996-8016. https://doi.org/10.1016/j.apm.2016.04.005.

772

773

774

775

776

777

778

779

780

781

782 